\title{
A Study on the Development of Tourist Support System Using ICT and Psychological Effects
}

\author{
Akira Sasaki ${ }^{1, *}$, Fu Xiang ${ }^{2}$, Rina Hayashi ${ }^{3}$, Yuko Hiramatsu ${ }^{4}$, Kazutaka Ueda ${ }^{5}$, \\ Yasunari Harada ${ }^{6}$, Hiroyuki Hatano ${ }^{7}$, Hiroshi Hasegawa ${ }^{1}$ and Atsushi Ito ${ }^{4, *(D)}$ \\ 1 Faculty of Engineering, Utsunomiya University, 7-1-2 Yoto, Utsunomiya, Tochigi 321-8585, Japan; \\ hasegawa@is.utsunomiya-u.ac.jp \\ 2 Zenrin Data Com Co., Ltd., Tamachi Station Tower N-22, msb Tamachi, 3-1-1 Shibaura, Minato-ku, \\ Tokyo 108-0023, Japan; x_fu@zenrin-datacom.net \\ 3 Okinawa Prefectural Government, 1-2-2 Izumizaki, Naha, Okinawa 900-8570, Japan; rina.h.1218@gmail.com \\ 4 Faculty of Economics, Chuo University, 742-1 Higashi Nakano, Hachioji, Tokyo 192-0351, Japan; \\ susana_y@tamacc.chuo-u.ac.jp \\ 5 Faculty of Engineering, University of Tokyo, 7-3-1 Hongo, Bunkyo-ku, Tokyo 113-8654, Japan; \\ ueda@hnl.t.u-tokyo.ac.jp \\ 6 Faculty of Law, Waseda University, 1-104 Totsukamachi, Shinjuku-ku, Tokyo 169-8050, Japan; \\ harada@waseda.jp \\ 7 Faculty of Engineering, Mie University, 1577 Kurimamachiya-cho, Tsu, Mie 514-8507, Japan; \\ hatano@elec.mie-u.ac.jp \\ * Correspondence: akira@gclue.jp (A.S.); atc.00s@g.chuo-u.ac.jp (A.I.)
}

Received: 21 October 2020; Accepted: 7 December 2020; Published: 14 December 2020

\begin{abstract}
We have been studying a sightseeing support application using Bluetooth Low Energy (BLE) beacons and mobile phones since 2014 to support sightseeing in Nikko, one of Japan's World Heritage sites. Travelers can receive information relating to their position by using this application. We tried to use some psychological effects to increase travelers' satisfaction when they receive such information. Moreover, we tried to emphasize travel memories of the place (scenery, culture, food, etc.) to encourage them to revisit or inspire their friends to visit it. Our tests prove the usefulness of our sightseeing support application for enhancing the travel experience. However, we had not yet developed a function to provide information that met the travelers' intentions or needs. Moreover, it is hazardous to use a smartphone during walking, especially in an unfamiliar place. If a traveler uses a smartphone during walking, they might miss the beautiful scenery, historic buildings, and exotic atmosphere. We tried to adapt our sightseeing support application for use with a wearable device (smartwatch) to avoid using a smartphone during walking and introduced a prospect theory to evaluate information according to personal interest and behavior. Our experiments proved that our application provided the most appropriate sightseeing information to travelers and prevented danger during walking.
\end{abstract}

Keywords: sightseeing support; travel psychology; BLE beacon; smartphone; wearable device; prospect theory; Maslow's hierarchy of needs; CogInfoCom; Zeigarnik effect

\section{Introduction}

In the "Tourism Vision for Tomorrow's Japan" [1], the government mentions a policy to develop "an environment where all travelers can enjoy tourism comfortably without stress" by utilizing Information Communications Technology (ICT) to promote inbound tourism and expand demand. In the "White Paper on Information and Communications 2016" [2] by the Ministry of Internal Affairs and Communications (MIC), personal blogs, travel portal sites, and HP of accommodation facilities 
are listed at the top as useful for foreign tourists to collect information before traveling. Furthermore, such information is becoming more multilingual and its utilization is progressing. However, to what extent can sightseeing be promoted by being "stress-free and comfortable"? Is it okay to deal with business tourists in the same way as tourists who visit Japan for leisure and fun? There is research showing that the essential feature of sightseeing is novelty [3], but what does the convenience of extending daily life bring to sightseeing? If the real pleasure of sightseeing is to stay in an unknown place away from the extension of daily life, ICT support for sightseeing does not necessarily lead to enjoying a stress-free time. However, sightseeing information is overflowing on the Internet. In particular, sightseeing sites based on social networking services (SNS), such as Qunar.Com and Trip Advisor, contain countless information generated by tourists themselves. Such information not only conveys the charm of the tourist spot to other tourists along with photographs, but also creates the satisfaction of the person who went to the tourist spot. This contributes to making tourism attractive. On the other hand, such a sightseeing support method has some problems. Usually, ordinary visits involve rushing to famous places in the area. However, local habits and unique sights that only local people know will not appear in such information sites except in rare cases. Even when they do, it is in the corner of guidebooks and websites and easy to miss. Therefore, if we could provide various types and levels of information according to tourists' needs, we could expect an improvement in their satisfaction. In the past, human guides develop interactions between a guide and tourists [4]. They have played roles such as increasing the value of travel, especially at historical areas $[5,6]$. Moreover, "local tour guides are key players in mediating tensions between concurrent processes of localization and globalization" [7]. However, with the diversification of travel, this is becoming more difficult. For example, if a traveler visited a city before sightseeing, he/she would like to see a different town area. However, for a traveler who has not visited there, he/she would like to see the most popular sightseeing point. In another case, if it is too cold and raining, travelers would like to visit a museum rather than climbing a hill. Therefore, each traveler needs different information during a trip. How can we use ICT to increase tourists' satisfaction and provide them with detailed information? We have been performing research to support tourism in Nikko, a World Heritage area in Japan, since 2014. Recently, the number of visitors to Nikko has decreased, so we aim to promote the Nikko area by supporting travelers using ICT.

This paper outlines our research history to develop a sightseeing support application by applying Bluetooth Low Energy (BLE) beacons and various psychological effects, especially for inbound travelers, and outlines the application based on behavioral economics developed last year to enable the optimum distribution of information.

The structure of this paper is as follows. Section 2 mentions related works. Section 3 introduces the enhancement of CogInfoCom model to meet our new sightseeing support application. In Section 4, we explain the history of studies on sightseeing support applications including psychological effects. Then, details of the behavior of the information delivery method based on behavioral economics are described in Section 5. Section 6 reports on the results of the experiments. Finally, a summary of our studies is given in Section 7.

\section{Related Works}

\subsection{Tourism and Psychology}

Some psychological studies exist as the basis of studies on tourism and psychology. A study about motivation is discussed in [8] using "Dynamic correlation model". Moreover, the authors of [9] explained long-term change of motivation using "Cross-lagged panel correlational model" and "Maslow's hierarchy of needs" [10]. In these studies, motivation is explained as the difference between positive impression and negative impression. To explain behavior prediction, the authors of [11] explain the case with multiple choices and the authors of [12] explain the importance of bland. 
Furthermore, some studies of motivation of trip have been performed based on these researches such as in [13].

Another direction is based on the mental model relating to a trip. A paper by Tae-Hee Lee and Crompton, J. [3] introduced the concept of "Tourism Novelty Scale". This idea is based on the idea that people want to travel to be something they cannot experience in their daily lives. In Japan, the authors of [14] analyzed the travel and introduced ideas similar to the "Tourism Novelty Scale". The peculiarities of tourism synchronization are discussed in [15], which introduces five motivations for sightseeing, i.e., to relieve tension (the pursuit of tension), to have fun (the pursuit of entertainment), to deepen relationships (or, strengthen relationships), to enrich knowledge (promotion of knowledge), and for self-growth (self-expansion). Although not necessarily in the same in terms, such work provides the basis for pursuing novelty in this research and establishing an evaluation axis. As an example of the use of psychological effects for sightseeing, the work in [16] introduced the idea of using the Zeigarnik effect [17] to increase repeaters. Some researchers used behavioral economics in travel planning to select transportation and optimize time $[18,19]$. However, there is no example of applying it to select information during the trip.

\subsection{Tourist Support by ICT}

\subsubsection{Smart Tourism}

There are many studies for the management of tourism using ICT.

"Smart tourism" is a word to describe a foundation of ICT-based tourism. Its definition is described as "to describe the increasing reliance of tourism destinations, their industries and their tourists on emerging forms of ICT that allow for massive amounts of data to be transformed into value propositions" in [20]. A similar word is "Smart Tourism Ecosystem (STE)" [21], which is a "digital ecosystems and smart business networks as conceptual building blocks". Furthermore, "Smart Tourism Destination (STD)" is a scenario for destination management as described in [22]. The importance to provide "personalized experiences" is mentioned in [23]. How the use of technology "before, during, and after" the visit influences the tourist experience is described in [24]. The new idea called "Ambient Intelligence (AmI) Tourism" is described in [25] to rebuild the ecosystem of tourism. The "Smart Tourism Technology (STT)" is an idea to support to decide the destination. The work in [26] described which information is useful to increase the satisfaction of the.

These researches provide a good idea of frameworks of tourism support by ICT; however, these researches do not mention evaluating the tourism support applications.

\subsubsection{Mobile Phone Applications}

The number of existing smartphone applications for sightseeing is huge [27]. They work as an electric version of guidebooks and usually provide information on restaurants, souvenirs, weather forecasts, MAP, etc. In Japan, there were 666 mobile applications for sightseeing as of March 2015 [28]; $96 \%$ of them are free. However, they are not used; $69 \%$ of them were downloaded less than 1000 , and $9.1 \%$ were downloaded less than 10,000. The average number of downloads of the pied application was less than 500 .

Some examples of sightseeing support applications are as follows.

A personalized sightseeing information application is explained in [29]. An application for cultural heritage recommendation is introduces in [30]. Moreover, a platform of sightseeing application for cultural heritage is discusses in [31].

\subsubsection{BLE Beacon}

IoT is now becoming popular, and there are researches using IoT for sightseeing. One of the most popular technologies of IoT is a beacon using Bluetooth Low Energy (BLE) [32]. BLE has a function to send an "advertising message" to notice a BLE device's existence. The outline of the behavior of BLE 
advertising is described in Figure 1. BLE has 40 channels, and a beacon uses three of them (channel 37, 38 , and 39) to send an advertising message in the prefixed interval. An advertising message can reach about $100 \mathrm{~m}$ on the street and $20 \mathrm{~m}$ in a forest in summer [33].

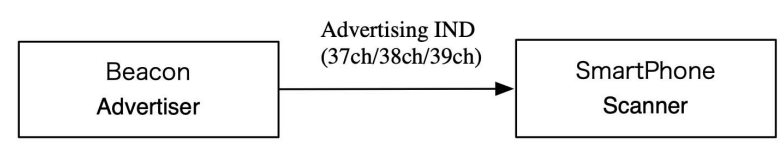

Figure 1. Advertising channels of Bluetooth Low Energy (BLE).

In an advertising message there are two pieces of crucial information: one is UUID that is a unique id of a BLE device (16 octets), and the other is Major/Minor flags (2 octets each). Such information is used to indicate the location of a beacon. There are many types of research to use BLE beacon for indoor navigation such as [34,35]. However, there are not so many studies using BLE beacon outdoor to provide sightseeing information.

In addition, the work in [36] discusses on ubiquitous indoor navigation without a smartphone. In Europe, there are some projects to use IoT for sightseeing. One example was TAG CLOUD (Technologies lead to Adaptability and lifelong enGagement with culture throughout the CLOUD) [37]. This is an information providing service that combines a smartphone with a QR code or IC tag at famous places in Europe (Alhambra in Spain, Trendaim in Norway, The Barber Institute of Fine Arts in the UK, etc.). However, the TAG CLOUD requires access to the cloud, and its usability is limited in suburbs and buildings where such access is difficult.

\section{CogInfoCom}

In this section, we discuss the relationship between the cognitive model of our application and the CogInfoCom model in $[38,39]$. The CogInfoCom model includes "intra-cognitive infocommunications" and "inter-cognitive infocommunications" (p. 77 in [38]). "Inter-cognitive infocommunications" describe the relationship between a human and sensors or other autonomous cognitive systems. However, in the case of a cognitive model of sightseeing, we have to consider our memory, in other words, the inside of our brain. Figure 2 presents an idea to extend "inter-cognitive infocommunications" to describe the cognitive model of sightseeing and our application that works with BLE beacons. In [40], we extended the original model outlined in [38]. Figure 2a shows the original model of "inter-cognitive infocommunications", and Figure $2 b$ is the extension of it to describe the cognitive model for sightseeing. The difference between Figure $2 a$ and Figure $2 b$ is the position of "cognitive informatics". In our sightseeing support system, BLE beacons are used only for providing location and not an active sensor. A smartphone receives a signal from the beacon, and a user reacts inspired by the information provided by the beacon. The activity causes the good or bad memory of the location and of the activity itself. This process is an example of cognitive informatics between the human activity and the memory in a brain. What is established between the location (beacon) and the cognitive model in a brain is instead an example of "inter-cognitive infocommunications". In this paper, we extend the model again as shown in Figure 2c. This figure introduces intra-cognitive informatics to explain the information delivery path between a smartphone and a tourist. Usually, a tourist uses a smartphone for navigation. However, using a smartphone during sightseeing, especially while walking, is dangerous. Moreover, a tourist may miss noticing the beautiful scenery and historic buildings while he/she looks at the small screen. Therefore, we think it is essential for a tourist to use a wearable device instead of a mobile phone. Figure $2 c$ explains that information from a smartphone is selected and prioritized based on his/her interest and behavior during sightseeing. A wearable device changes media of communication using vibration or audio. We defined this process as "intra-cognitive information". We think selection and prioritization are essential for a tourist in this model. One of the problems in retrieving the information about a traveling area is the presence of excessive information on the Internet. If a tourist can use a smartphone, he/she can select the most appropriate information 
from the content listed on the screen. However, if a tourist does not use a smartphone, he/she can receive a small amount of information. Therefore, the quality and value of information should be high and minimized after the filtering. In this paper, we would like to explain how we designed the "intra-cognitive information" function in our sightseeing support application and discuss the results of our experiments.

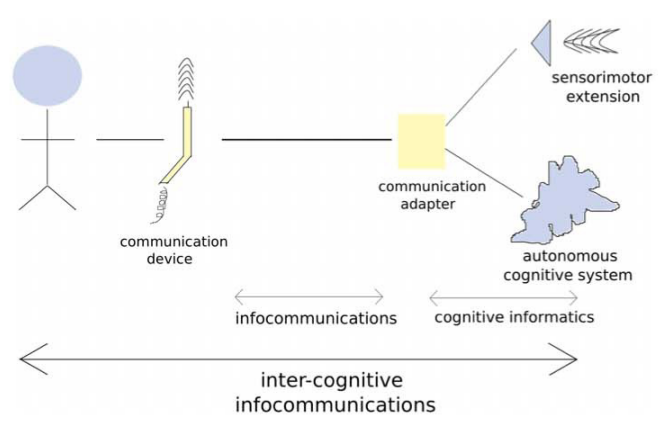

(a) Original inter-cognitive infocommunications

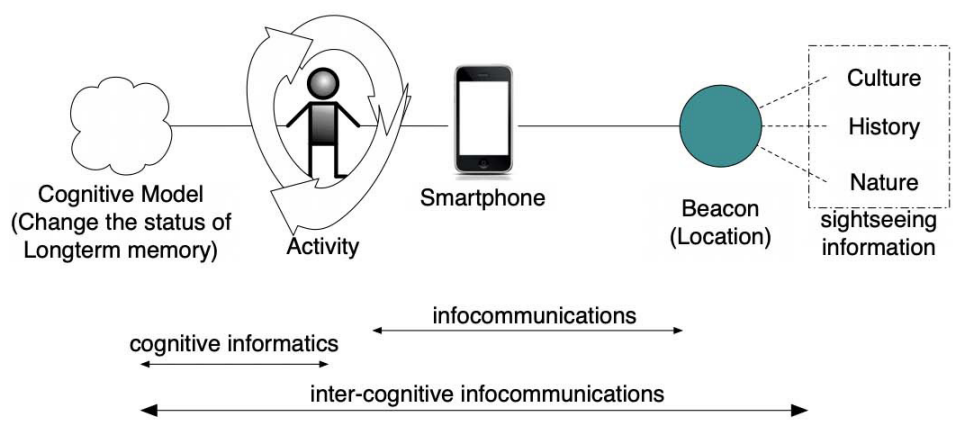

(b) Extension of inter-cognitive infocommunications

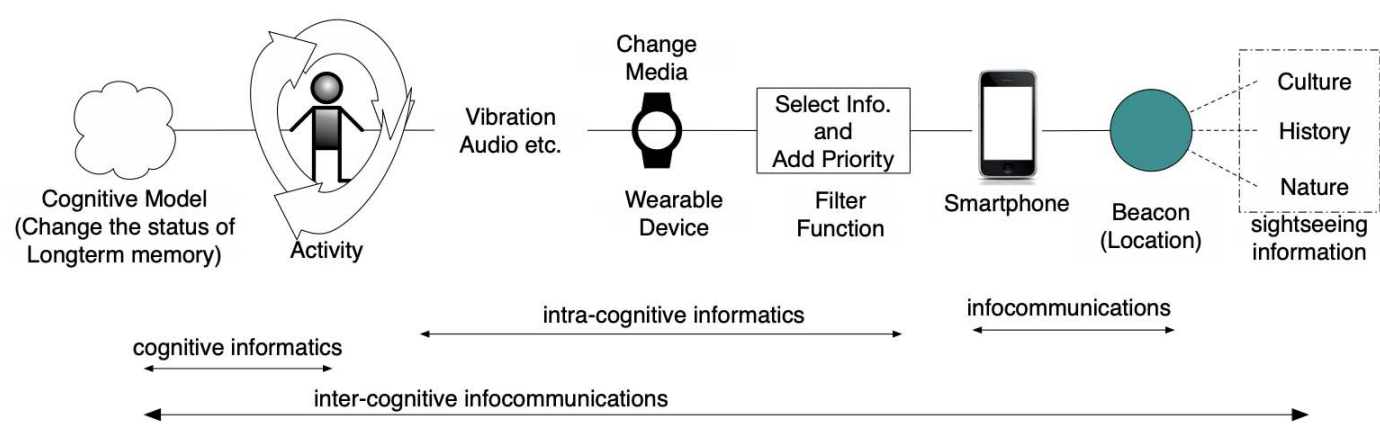

(C) Extension to introduce intra-cognitive infocommunications

Figure 2. The relation between a cognitive model of our application and original CogInfoCom model/ / Extension to introduce intra-cognitive infocommunications.

\section{History of the Development of a Sightseeing Support Application for Nikko}

As explained in the previous section, we have been developing a sightseeing support application for inbound travelers since 2014 in the Nikko area. We first investigated what is the most attractive aspect of travel in Nikko [41]. Then, we tried to increase the expectation and satisfaction of travel. Nikko is one of the world heritage sites in Japan. There is the Toshogu Shrine [42] that is a gorgeous grave of Ieyasu Tokugawa, the first Shogun of the Tokugawa Era. However, now, Nikko is not so famous for foreigners. Research by travel agency displayed that Nikko is not listed in the top 30 locations where foreigners would like to visit [43]. 
In the Nikko area, tourists who walk from the Nikko Station to the Toshogu Shrine are mainly inbound tourists. They require support from smartphone applications since they are not familiar with the Nikko area. We used BLE beacons instead of GPS as GPS has a high battery consumption and is thus not suitable for sightseeing [44]. The outline of the information delivery using BLE beacons and a smartphone is described in Figure 3.

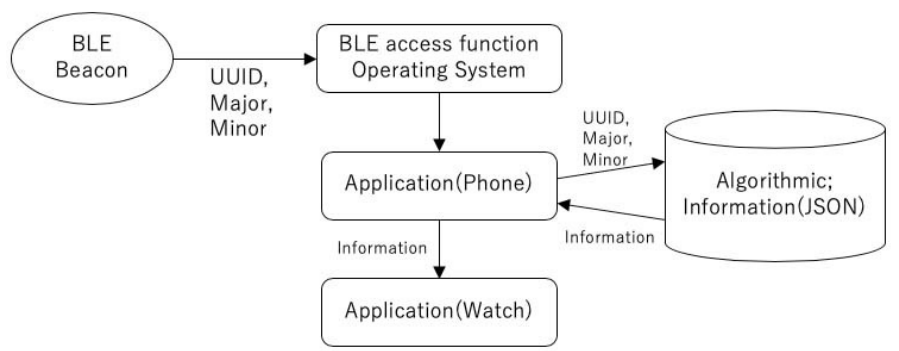

Figure 3. Delivering sightseeing information by BLE beacon.

Figure 4 shows the photos of BLE beacon used in Nikko along the road from Nikko Station to Toshogu Shrine. Our research is separated into three parts, as described in Figure 5. In the following subsections, we explain the outline of each phase.
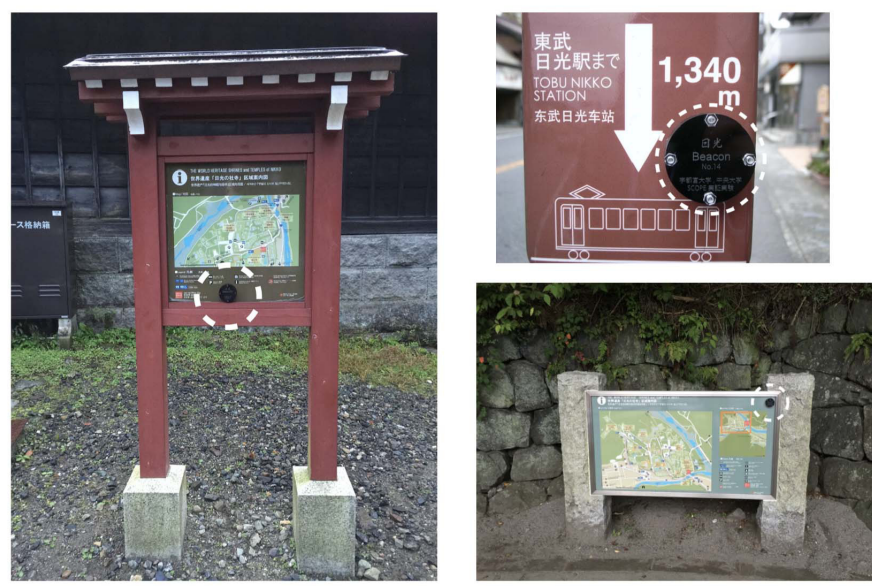

Figure 4. BLE beacons on the street in Nikko (in a white dotted circle).

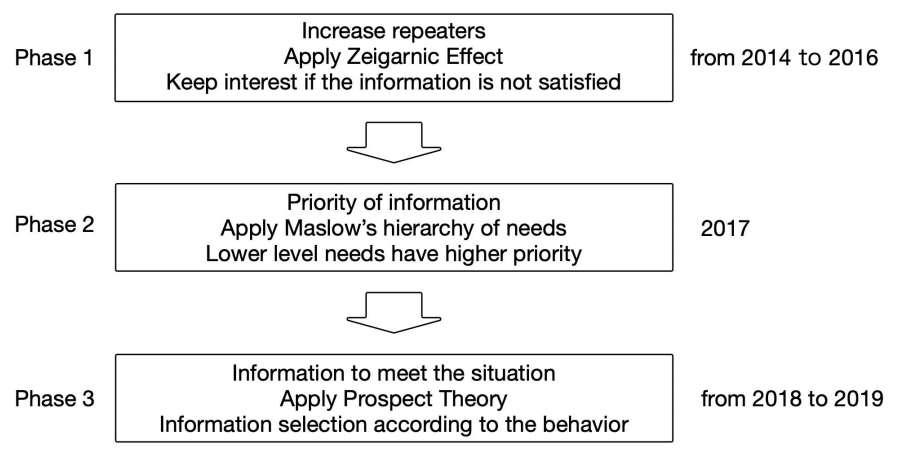

Figure 5. Project flow.

\subsection{Phase1: Increase Repeaters}

We performed research to develop sightseeing support information to increase tourists' satisfaction from 2014 to 2016 [44-46]. A survey of tourists' images of Nikko and verification of the effectiveness of using the app revealed that a large amount of information does not become effective to increase the number of tourists [47]. Therefore, we focused on the Zeigarnik Effect as a way 
to evidence the charm of travel and constructed a cognitive model of travel (Figure 6). According to the research studies on the psychology of sightseeing, travel is divided into three stages, i.e., before the trip, during the trip, and after the trip [15].

We extended this model based on the memory of a trip. A trip starts with expectations before the trip. If there is an element which has been "forgotten" or left a feeling of "unsatisfaction" in the awareness during the trip and in the memories after the trip, it will be kept long in the memory and trigger a revisit. Following this idea, our model of sightseeing has an "unknown" part. We used the Zeigarnik Effect to produce something "forgotten" or related with "unsatisfaction". The Zeigarnik Effect is a psychological effect. If a person received incomplete information, he/she retains an interest in that aspect. It is possible to increase satisfaction and expectation if the information is partially hidden. We used a quiz-rally application to evaluate the effectiveness of the Zeigarnik Effect. Some quizzes were presented near a sightseeing spot, and a tourist was able to check the answer at that point. If the quiz was difficult and unfinished, the related feeling of dissatisfaction promoted interest and memory. We checked the memory of the testers about the Nikko area four times just before the trial, just after the trial, one month after, and two months after.

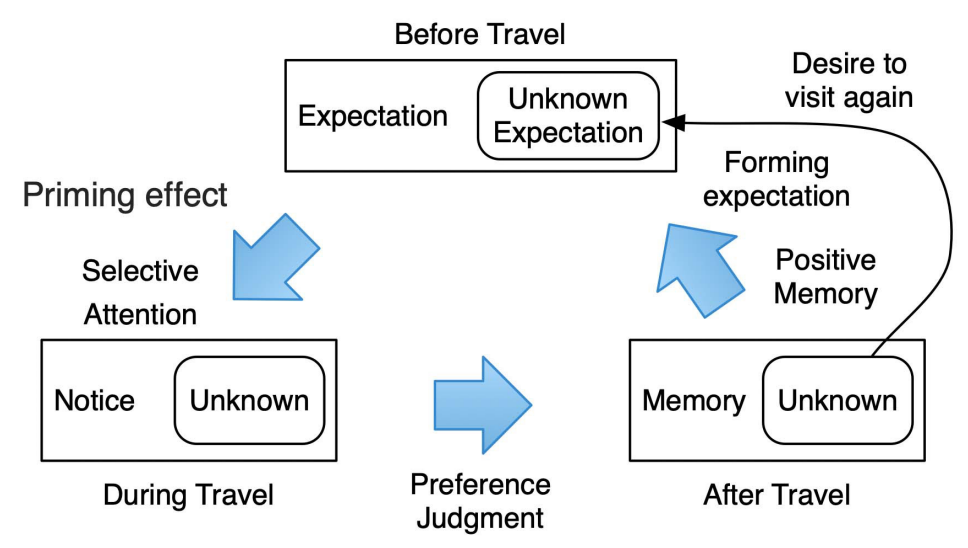

Figure 6. Cognitive model for sightseeing.

In 2016, from September to December, we had several trials. A total of 18 students cooperated to evaluate our cognitive model's effectiveness to increase the impression of Nikko. They walked from Nikko Station to Toshogu Shrine following our navigation application "Nikko Kamen Navi" by answering quizzes. Just after they finish sightseeing, we asked two questions.

- Q1: the impression about the application (5 levels Liker scale)

- Q2: the impression of Nikko (5 levels Liker scale)

Two months after, we asked them about the impression of Nikko by using the same questioner. We got 3 clusters by analysis of Q1 as follows.

- Cluster $1(\mathrm{n}=7)$ : appreciated sound, color, and expression

- Cluster $2(\mathrm{n}=7)$ : appreciated overall impression and UX

- Cluster $3(n=4)$ : appreciated quiz contents and visibility of the map

Table 1 shows the impression of Nikko on each cluster, the left side is just after the walking, and the right side is two months after. The bold font in the table means that the point was increased +0.5 or more two months after. The impression was emphasized in Cluster 3, who appreciated quiz contents. We can conclude that this is one of the pieces of evidence to prove the effectiveness of our cognitive model for sightseeing and the Zeigarnic Effect. We introduced the idea of the Zeigarnic Effect and our cognitive model to add an "unknown part" in the contents. A more detailed discussion is described in [45]. 
Table 1. The difference of impression of Nikko results after two months.

\begin{tabular}{|c|c|c|c|c|c|c|c|}
\hline \multicolumn{4}{|c|}{ Just after Visit } & \multicolumn{4}{|c|}{2 Months after } \\
\hline Questions & Cluster 1 & Cluster 2 & Cluster 3 & Questions & Cluster 1 & Cluster 2 & Cluster 3 \\
\hline Nature & 4.57 & 4.86 & 4.00 & Nature & 4.43 & 4.83 & 4.50 \\
\hline History/Culture & 4.29 & 5.00 & 3.50 & History/Culture & 4.43 & 4.80 & 4.75 \\
\hline City Scape & 4.14 & 3.86 & 4.00 & City Scape & 4.00 & 3.83 & 4.00 \\
\hline Hot Spring & 4.00 & 3.71 & 3.50 & Hot Spring & 3.57 & 3.50 & 3.25 \\
\hline $\begin{array}{l}\text { Traditional } \\
\text { culture }\end{array}$ & 3.43 & 3.86 & 3.00 & $\begin{array}{l}\text { Traditional } \\
\text { culture }\end{array}$ & 3.71 & 3.83 & 4.00 \\
\hline Foods & 3.86 & 4.00 & 3.50 & Foods & 3.71 & 3.83 & 4.75 \\
\hline Activity & 3.00 & 3.43 & 2.25 & Activity & 3.00 & 2.83 & 3.75 \\
\hline Shopping & 3.00 & 3.29 & 2.75 & Shopping & 3.00 & 3.17 & 3.75 \\
\hline Night Spots & 2.86 & 2.71 & 3.50 & Night Spots & 3.00 & 2.67 & 3.00 \\
\hline $\begin{array}{l}\text { Interaction with } \\
\text { local people }\end{array}$ & 3.00 & 3.43 & 2.25 & $\begin{array}{l}\text { Interaction with } \\
\text { local people }\end{array}$ & 3.71 & 3.33 & 3.00 \\
\hline $\begin{array}{l}\text { Reservation of } \\
\text { Accommodation }\end{array}$ & 3.14 & 3.29 & 3.50 & $\begin{array}{l}\text { Reservation of } \\
\text { Accommodation }\end{array}$ & 3.00 & 3.17 & 3.00 \\
\hline $\begin{array}{l}\text { Price/quality of } \\
\text { Accommodation }\end{array}$ & 3.43 & 3.71 & 3.25 & $\begin{array}{l}\text { Price/quality of } \\
\text { Accommodation }\end{array}$ & 3.00 & 3.17 & 3.50 \\
\hline $\begin{array}{c}\text { Convenience of } \\
\text { Access }\end{array}$ & 3.86 & 4.43 & 2.75 & $\begin{array}{c}\text { Convenience of } \\
\text { Access }\end{array}$ & 3.29 & 3.50 & 1.75 \\
\hline Price & 3.14 & 3.43 & 2.25 & Price & 3.00 & 3.83 & 3.25 \\
\hline
\end{tabular}

\subsection{Phase 2: Classification of Sightseeing Information According to the Priority and UI Design}

What kind of information is required when traveling for sightseeing purposes? The mental model of sightseeing does not answer this question. The information required for sightseeing was diverse, and in our analysis, it covered ten categories and 50 items, as explained in Figure 7 . We used Maslow's hierarchy of needs [10,48] to design the UI of the sightseeing application. Next, we mapped the information into Maslow's hierarchy of needs, as shown in Table 2. We did not use the 7th layer, "Self-actualization needs", as this need is not directly related to sightseeing.

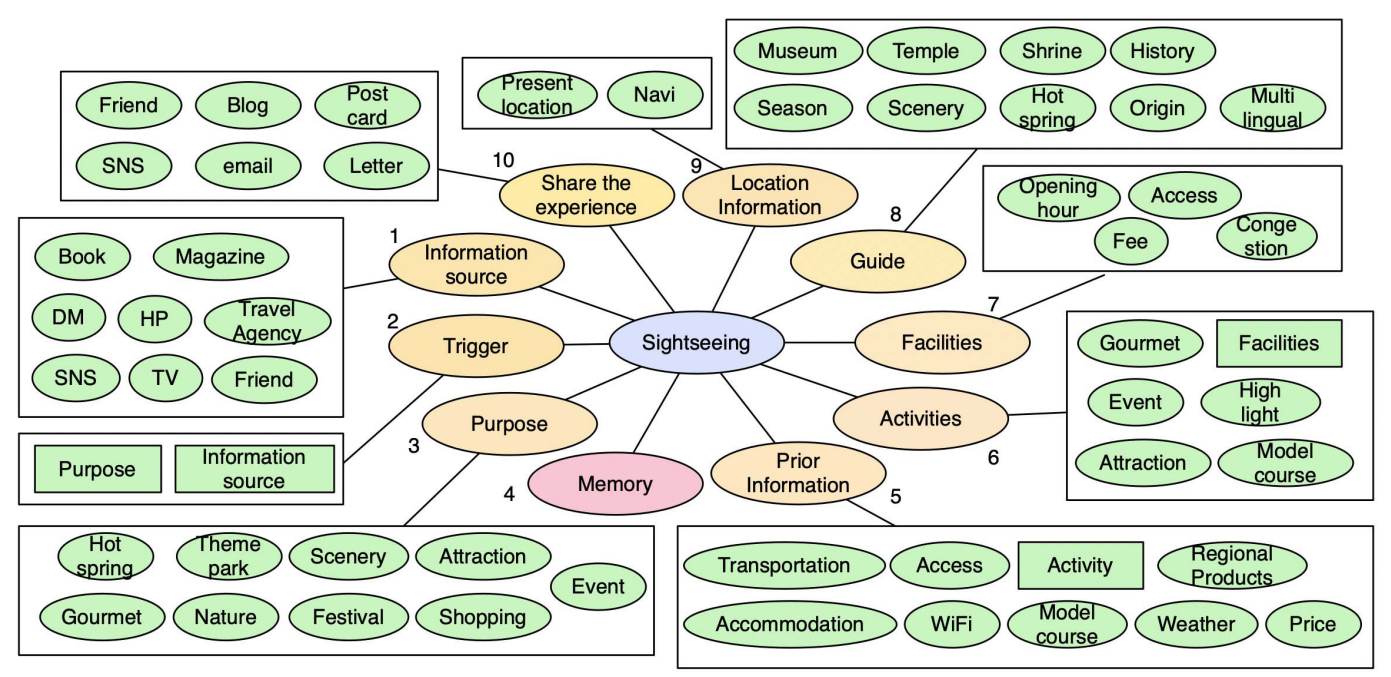

Figure 7. Categories of information of sightseeing. 
Table 2. Mapping among elements of sightseeing information and Maslow's hierarchy of needs.

\begin{tabular}{|c|c|c|}
\hline Level & Needs & Element of Sightseeing Information \\
\hline 1 & $\begin{array}{l}\text { Biological and physiological needs (such as } \\
\text { hungry, thirsty) }\end{array}$ & Food and drink, Restroom \\
\hline 2 & Safety needs (such as protection, security) & $\begin{array}{l}\text { Transportation, Access, Accommodation, Wi-Fi, } \\
\text { Price, Weather, Crowd, Disaster prevention, } \\
\text { Dangerous animal, Map, Multilingual }\end{array}$ \\
\hline 3 & $\begin{array}{l}\text { Love and belongingness needs (such as } \\
\text { connecting friend) }\end{array}$ & SNS, Word of mouth, Letter, Postcard \\
\hline 4 & Esteem needs (Get evaluation and certification) & Response on SNS such as press the like button \\
\hline 5 & Cognitive needs (such as know, understand) & Famous sightseeing spots, Model courses, Events \\
\hline 6 & $\begin{array}{l}\text { Aesthetic needs (such as harmony, order, } \\
\text { beauty) }\end{array}$ & $\begin{array}{l}\text { Explanation of history, Photos of scenery, animals } \\
\text { and plants }\end{array}$ \\
\hline
\end{tabular}

Then, we designed a UI based on the mapping among sightseeing information elements and Maslow's hierarchy of needs. The UI contains several buttons, such as "Weather", "Information", "Timetable of a bus", "Map (current position, restroom, visitor center, rest house)", "Information on the area (nature guide, shops)", "Photos of seasons", "Guidebook of birds, flowers and mountains", "Stamp Rally", "Pop-up information according to the received beacon signal", "SNS", and "Setting". We tested two patterns: in the first pattern, levels 1 and 2 had higher priority (Layout-1), while in the second one level 5 and 6 had higher priority (Layout-2).

The two UI designs are shown In Figure 8. Moreover, we introduced buttons to access photos of four seasons and photo books of nature (mountain, flower, and bird) on the home screen. We tried to tempt a user to visit Oku-Nikko at the different seasons to introduce the Zeigarnic Effect in this application.

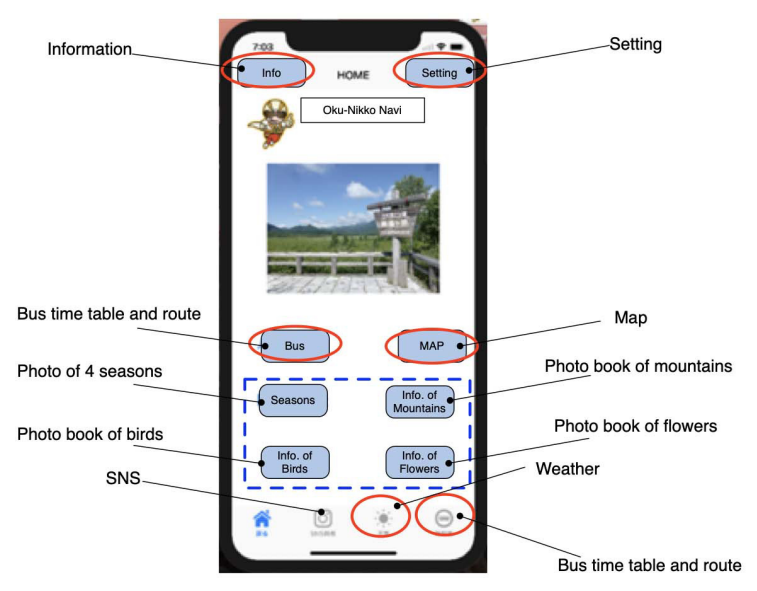

Layout-1

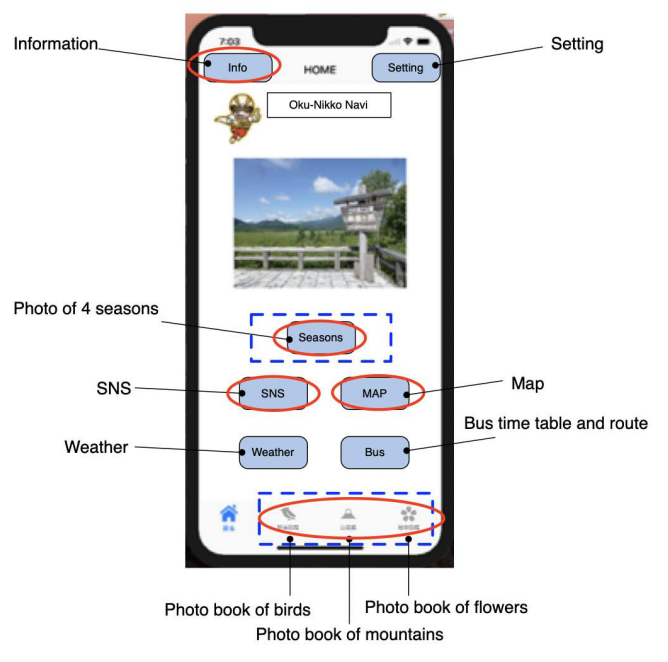

Layout-2

Figure 8. Two different designs of UI: the left one was designed based on layer 1 and 2, and the right one was designed based on layer 5 and 6 .

The outline of the experiment is described in Figure 9.

We performed an experiment to compare these applications.

The experiment was held from 19 February 2018 to 21 February 2018. Twenty students, eighteen male and two female, joined the experiment. After using the application, we asked them about the impression of the application by using the questioner. Some of the questions are listed below. 
- What was the useful information (multiple selections are possible)

- What was the impressive information (multiple selections are possible)

- The following ten items are evaluated on a scale of 1 (not good) to 5 (very good).

1. Easy to operate

2. The characters are easy to read

3. The amount of information is appropriate

4. Good design

5. Easy to read map

6. Ease of use of bus timetable

7. The button layout is correct

8. The pop-up is easy to see

9. The pop-up information is appropriate

- Impression of the app (multiple selections allowed)

- Impressions using the app (free description)

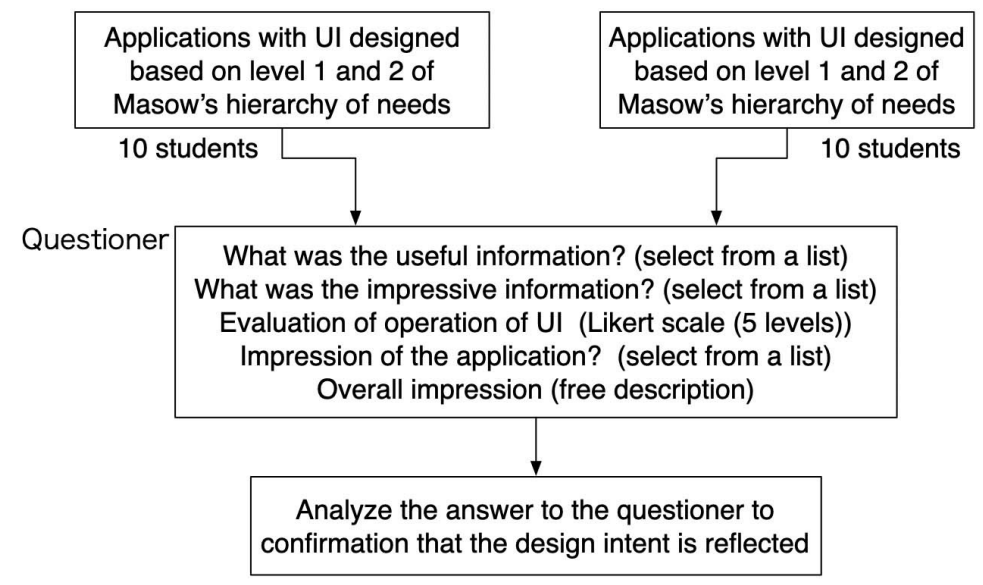

Figure 9. Two different designs of UI: the left one was designed based on layers 1 and 2, and the right one was designed based on layers 5 and 6 .

The impression of information is summarized in Figure 10.

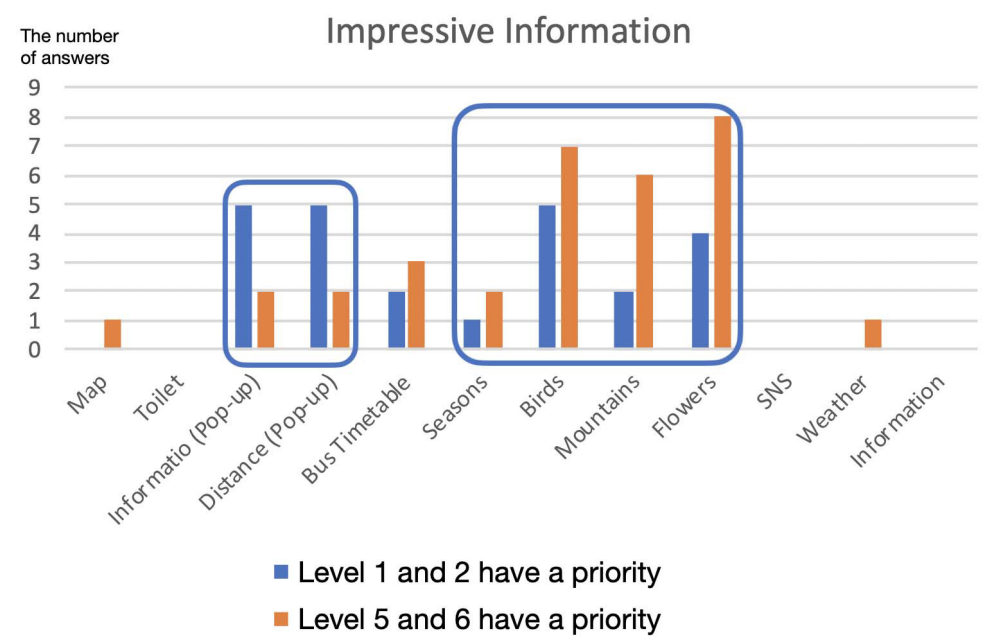

Figure 10. Two different designs of UI: the left one was designed based on layers 1 and 2, and the right one was designed based on layers 5 and 6. 
As a result, when Layout-1 was used, the information on surrounding areas and on the time required to reach bus stops and major sightseeing spots included in restroom information and pop-ups using beacons was highly evaluated. When Layout-2 was used, the guidebook of birds, flowers, and mountains was highly evaluated. We think that the UI design based on the mapping among sightseeing information elements and Maslow's hierarchy of needs is valuable.

The detailed discussion is described in $[49,50]$.

\subsection{Phase3: Optimization of Delivered Information}

As explained in Section 3, one critical issue in using a smartphone for sightseeing is that there is too much information. Too much information not only makes selection difficult but also denies or complicates access to the information. This is a phenomenon called overload of clue [51]. In the information delivery using the BLE beacon that we are developing, one beacon provides one information. However, it is necessary to link various information to the beacon for practical use. For example, around a BLE beacon, there are not only shrines and temples but also souvenir shops and restaurants. However, of all that information, what is the most relevant for tourists? For example, it is conceivable to obtain the user's profile and send the most appropriate information in consideration of triggers such as position and time. However, it is difficult to formulate a strategy for providing information that also assumes the user's psychological and physical conditions. As a result, it is expected that similar information will be provided to tourists in the same pattern. It is essential to select and provide the most appropriate and in-demand information from the uncountable bits of information to increase tourists' satisfaction. As shown in Figure 11, sightseeing information is to be provided following the change of user requirements. To implement a function to realize such a procedure, we first consider the value of information for each tourist and situation. Moreover, this function represents the "intra-cognitive informatics" as described in Figure 2.

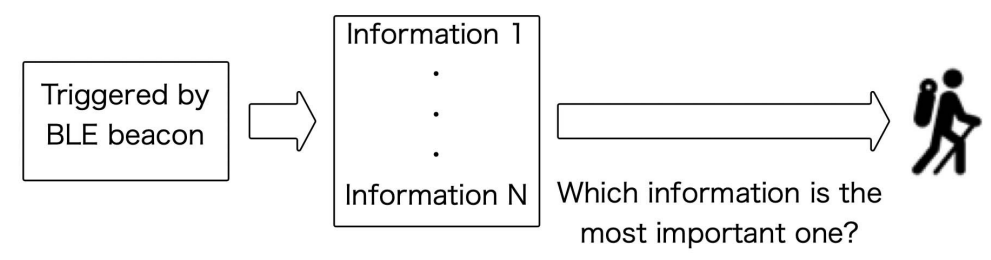

Figure 11. A model to provide information.

Prospect Theory $[52,53]$ is one of the important theories in behavioral economics. The theory has the following three features.

- Reference Point is used for evaluation

- Diminishing Sensitivity

- Loss Aversion

Figure 12 shows a graph to explain the Prospect Theory [54]. This graph explains that the loss gives larger mental damage rather than gain. We tried to apply this idea to our sightseeing support application. It means deciding the information to be delivered based on the psychological value. According to Figure 12, if the value of the information is left as the reference point (the origin of the graph), the psychological value should be considered lower. The reference point is also changed by many reasons such as the knowledge and experiences, history of the daily behavior of a day of a tourist. If we can follow the change of the reference point, in other words, the mental state of a tourist, we think that it is possible to provide sightseeing information to increase travel expectation of the travel and satisfaction of the tourist. 


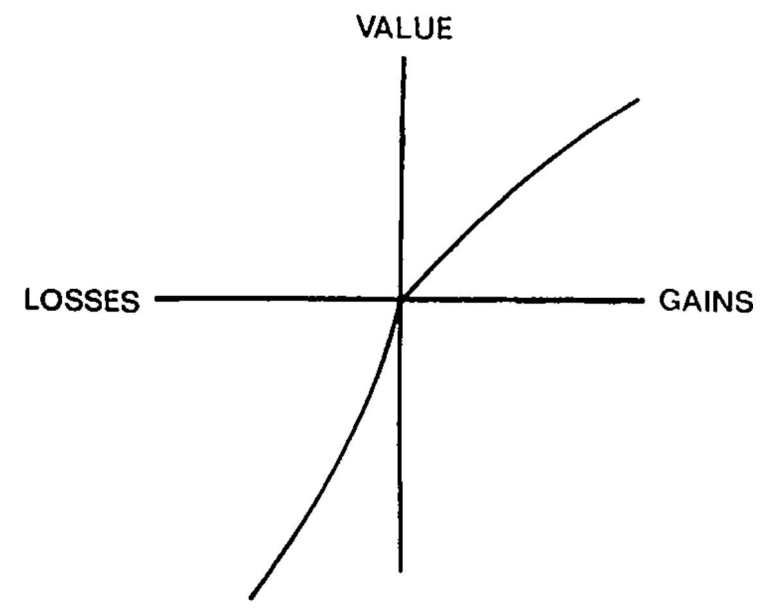

Figure 12. Prospect theory.

\section{Providing Information Based on Prospect Theory}

\subsection{Outline of the Technology for Providing Sightseeing Information}

In this section, we explain our idea to provide appropriate information to a tourist. Original Prospect Theory is used to describe the value or impression according to an input such as earned money. However, in our sightseeing support system, the value of information varies according to the situation. For example, the information regarding the restaurant is valuable if it is provided when a tourist is hungry; whereas, the information is not valuable just after lunch. Therefore, it is important to change the value of the information in real-time, which can be carried out in two ways: The first way is to change the value of the information itself, and the other is to change the baseline of the evaluation. In the application, according to the limited calculation and storage resources, it is difficult to calculate the value while considering additional surrounding information. Therefore, we explained value as the difference between the predefined information value and the baseline of the evaluation. If a tourist is satisfied with the provided information, the baseline is up, and if they receive the information again, the value is slightly lower than the original value. According to the psychological state, if the information is not useful for a tourist, the value becomes poor, and the dissatisfaction level and mental damage increase. We tried to reflect the difference between positive and negative mental reaction in the information value evaluation algorithm that is based on the Prospect Theory.

\subsection{Calculation of the Initial Value of Information}

To calculate the value of information based on Prospect Theory, we classified information for sightseeing into four categories based on Maslow's hierarchy of needs as described in Table 3.

As the basis of the classification of sightseeing information, we used levels 1, 3, 5, and 6 of Maslow's hierarchy of needs. The reasons why we did not use levels 2, 4, and 7 are as follows. Level 2 is a "safety" need. Between the Nikko Station and Toshogu Shrine, that area is Nikko's central part and a very safe place. Therefore, it is no need to provide safety information to a tourist. Level 4 is "esteem" needs, such as posting information to SNS so that such information is not needed to be provided by sightseeing application. Level 7 is "self-actualization" needs, and there is no need to provide such information.

We set some value factors that should affect the value of sightseeing information, which are based on the characteristics of the categories. Table 4 shows an example of the value factors of sightseeing information. The value factor index (I) was set in five stages, which ranged from 1 (lowest) to 5 (highest). 
For example, based on a restaurant's information included in Maslow's biological and physiological needs, three information, i.e., "interest", "rareness", "environment", and "location" are set. At the start of the application, the "interest" is the information provided in the questionnaire. The "rareness", "environment", and "location" are obtained when the information is added in the application's database. For example, "JR Nikko Station" has the following information, as described in Table 5.

- Maslow's hierarchy of needs: Aesthetic needs

- Category of information: Landmark

- Value factors: Rarity:3, Attraction:2

Table 3. Classification of information based on the idea of Maslow's hierarchy of needs.

\begin{tabular}{ll}
\hline Level of Needs & Contents \\
\hline (1) Biological and physiological needs & Sweets \\
& Restaurant \\
\hline (3) Love and belongingness needs & Post office \\
& Souvenier \\
\hline (5) Cognitive needs & Musium \\
& Information center \\
& Event/Attraction \\
\hline (6) Aesthetic needs & Nature/Scenery \\
& History/Culture \\
& Landmark \\
\hline
\end{tabular}

Table 4. Category and value factors.

\begin{tabular}{ll}
\hline Category & Value Factors \\
\hline (1) Biological and physiological needs & Interest, Rarity, Environment, Location \\
(3) Love and belongingness needs & Interest, Rarity, Location \\
(5) Cognitive needs & Interest, Complexity, Rarity \\
(6) Aesthetic needs & Interest, Rarity, Attraction \\
\hline
\end{tabular}

Table 5. Details of sightseeing information.

\begin{tabular}{|c|c|c|c|c|c|c|}
\hline \multirow[t]{2}{*}{$\begin{array}{c}\text { Name of } \\
\text { Information }\end{array}$} & \multirow[t]{2}{*}{ Explanation } & \multirow[t]{2}{*}{$\begin{array}{l}\text { Maslow's Hierarchy } \\
\text { of Needs }\end{array}$} & \multirow[t]{2}{*}{$\begin{array}{l}\text { Category of } \\
\text { Information }\end{array}$} & \multicolumn{3}{|c|}{ Value Factors } \\
\hline & & & & Rarity & Attraction & Interest \\
\hline JR Nikko Station & History & Aesthetic & Landmark & 3 & 2 & Set by user \\
\hline
\end{tabular}

\subsection{Modification of Prospect Theory}

In this subsection, we explain the formula for evaluating the value of information based on the modified Prospect Theory.

$$
\begin{gathered}
U=\sum_{i=1}^{n} W_{i} \cdot V\left(\Delta I_{i}\right) \\
V\left(\Delta I_{i}\right)=\left\{\begin{array}{c}
\Delta I_{i}^{\alpha}, \Delta I_{i} \geq 0 \\
-\lambda\left(-\Delta I_{i}\right)^{\beta}, \Delta I_{i}<0 \\
\Delta I_{i}=I_{i}-I_{0} \\
{\left[a_{i j}\right]=\frac{W_{i}}{W_{j}}}
\end{array}\right.
\end{gathered}
$$




$$
\begin{aligned}
A\left[\begin{array}{c}
W_{1} \\
W_{2} \\
\cdots \\
W_{n}
\end{array}\right]=\left[\begin{array}{llll}
\frac{W_{1}}{W_{1}} & \frac{W_{1}}{W_{2}} & \cdots & \frac{W_{1}}{W_{n}} \\
\frac{W_{2}}{W_{1}} & \frac{W_{2}}{W_{2}} & \cdots & \frac{W_{2}}{W_{n}} \\
\cdots & & & \\
\frac{W_{n}}{W_{1}} & \frac{W_{n}}{W_{2}} & \cdots & \frac{W_{n}}{W_{n}}
\end{array}\right] \times\left[\begin{array}{c}
W_{1} \\
W_{2} \\
\cdots \\
W_{n}
\end{array}\right] \\
=n\left[\begin{array}{c}
W_{1} \\
W_{2} \\
\cdots \\
W_{n}
\end{array}\right]
\end{aligned}
$$

Formula (1) is used to calculate the value of information based on the Prospect Theory. The meaning of each parameter is as follows.

- $\quad U$ : Utility (=overall value)

- $W_{i}$ : Probability weighting function

- $I_{i}$ : Value factor

- $V\left(\Delta I_{i}\right)$ : Value function

Value function $V\left(\Delta I_{i}\right)$ is defined as Formula (2), where $\alpha=\beta=0.88, \lambda=2.25$ as described in [53]. $\Delta I_{i}$ in (1) and (2) is a value between the current value and the value of the reference point. Using this parameter, we tried to control the change of value according to the situation.

There are several ways to calculate the probability weighting function $W_{i}$. We used the Analytic Hierarchy Process (AHP) to calculate value factors [55] because it is possible to use the structure of the information value. AHP can be used to determine the importance between the whole and items from a paired comparison using the ratio of importance of each evaluation item. This is shown in Formula (4), where $W$ is the importance of information and $i, j$ are the numbers relating to value factors. Paired comparison matrix $\mathrm{A}=\left[a_{i j}\right]$ is shown in Formula (5), $n$ is the eigenvalue of matrix $A$. By finding the eigenvector for the maximum eigenvalue, the probability of each value factor $W_{i}$ can be calculated, and the value $U$ of sightseeing information can be calculated.

A reference point is set to each category that is classified by using Maslow's hierarchy of needs. As explained in Figure 13, after the proposed information is evaluated by a tourist, the value of the relating reference point is recalculated. The rule of changing reference point is described in Table 6. Sometimes the value of the reference point increases or decreases monotonously. To prevent the difficulty of calculating the value, we set the range of the reference point from 1 to $\mathrm{N}$ (odd number) and the initial value is $\left\lceil\frac{N}{2}\right\rceil$. If the value of the reference point reaches 1 or $N$, the value returns to $\left\lceil\frac{N}{2}\right\rceil$.

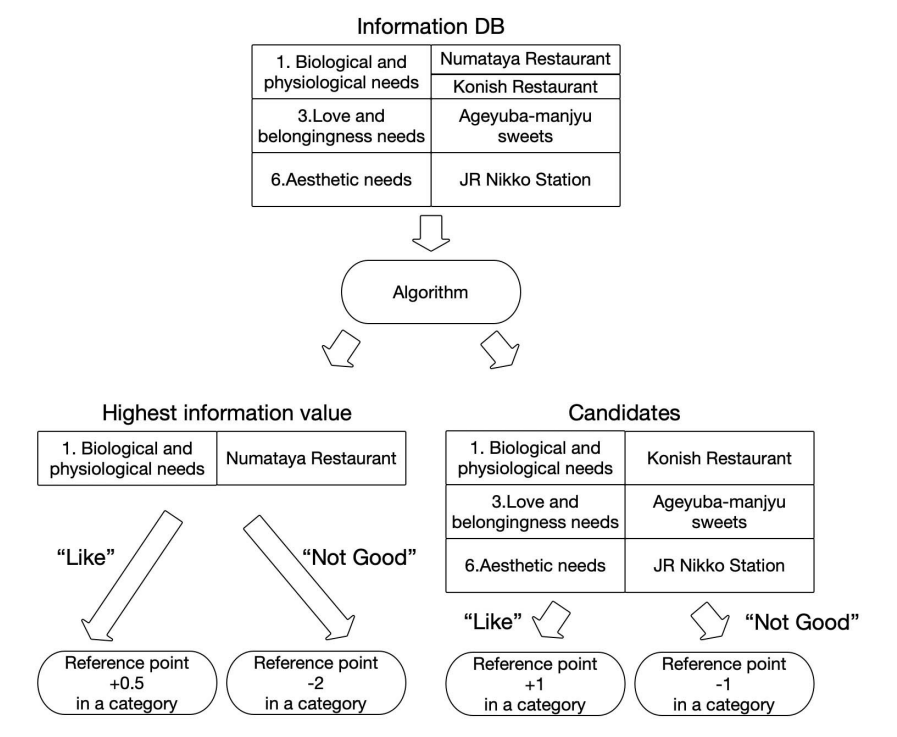

Figure 13. Evaluation of information and update of the reference point. 
Table 6. Change of reference point.

\begin{tabular}{cccc}
\hline \multirow{2}{*}{ Change of Reference Point } & & \multicolumn{2}{c}{ Information } \\
\cline { 3 - 4 } & & Responded & Not Responded \\
\hline \multirow{2}{*}{ Evaluation } & Good & 0.5 & 1 \\
\cline { 2 - 4 } & Not Good & -2 & -1 \\
\hline
\end{tabular}

\subsection{Example of Calculation of the Value of Information}

\subsubsection{Calculation of the Original Value of Information}

We assume that the value factor $I_{1}=5$, value factor $I_{2}=4$, and value factor $I_{3}=3$ are set and the reference points range from 1 to 5 . By using the Formula (3), the original information value is $\Delta I_{i}=I_{i}$ because $I_{0}=0$. From the Formula (2), $V\left(\Delta I_{1}\right)=\Delta I_{1}{ }^{\alpha}=5^{0.88}, V\left(\Delta I_{2}\right)=\Delta I_{2}{ }^{\alpha}=4^{0.88}$, $V\left(\Delta I_{3}\right)=\Delta I_{3}{ }^{\alpha}=3^{0.88}$. Then, the probability weighting function $W_{i}$ is calculated by using Formulas (4) and (5), and the decision matrix is shown in Table 7. The result is shown in Table 8.

Table 7. Decision matrix of $I_{0}$.

\begin{tabular}{lccc}
\hline & Value Factor $\boldsymbol{I}_{\mathbf{1}}$ & Value Factor $\boldsymbol{I}_{\mathbf{2}}$ & Value Factor $\boldsymbol{I}_{\mathbf{3}}$ \\
\hline Value factor $I_{1}$ & 1 & 1.25 & 1.67 \\
Value factor $I_{2}$ & 0.8 & 1 & 1.33 \\
Value factor $I_{3}$ & 0.6 & 0.75 & 1 \\
\hline
\end{tabular}

Table 8. The result of calculation of $W_{1}$ from $I_{0}$.

\begin{tabular}{ccc}
\hline Item & Eigenvector & Weight \\
\hline Value factor $I_{1}$ & 1.25 & 0.4167 \\
Value factor $I_{2}$ & 1 & 0.3333 \\
Value factor $I_{3}$ & 0.75 & 0.2500 \\
\hline
\end{tabular}

As a result, $W_{1}=0.4167, W_{2}=0.333$, and $W_{3}=0.2500$. Then, from the Formula (1), $U=\sum_{i=1}^{n} W_{i} \cdot V\left(\Delta I_{i}\right)$, the original information value is calculated as $U=5^{0.88} * 0.4167+4^{0.88} *$ $0.3333+3^{0.88} * 0.25=3.5038$.

\subsubsection{Calculation of Value Factor $I_{0}$ Relating to a Reference Point}

First, we assume $I_{1}=I_{2}=\cdots=I_{n}$. The probability weighting function $W_{i}$ is calculated by applying AHP, as explained in Formulas (4) and (5). The initial value of the decision matrix is described in Table 9. The result is shown in Table 10.

Table 9. Decision matrix of $I_{0}$ relating to a reference point.

\begin{tabular}{lccc}
\hline & Value Factor $\boldsymbol{I}_{\mathbf{1}}$ & Value Factor $\boldsymbol{I}_{\mathbf{2}}$ & Value Factor $\boldsymbol{I}_{\mathbf{3}}$ \\
\hline Value factor $I_{1}$ & 1 & 1 & 1 \\
Value factor $I_{2}$ & 1 & 1 & 1 \\
Value factor $I_{3}$ & 1 & 1 & 1 \\
\hline
\end{tabular}

Table 10. Calculation of $W_{i}$ from $I_{0}$

\begin{tabular}{ccc}
\hline Item & Eigenvector & Weight \\
\hline Value factor $I_{1}$ & 1 & 0.3333 \\
Value factor $I_{2}$ & 1 & 0.3333 \\
Value factor $I_{3}$ & 1 & 0.3333 \\
\hline
\end{tabular}


As the result, $W_{1}=W_{2}=W_{3}=0.3333$ are obtained. If the value of a reference point is 3, $U=W_{1} * V\left(\Delta I_{1}\right)+W_{2} * V\left(\Delta I_{2}\right)+W_{3} * V\left(\Delta I_{3}\right)=3$ are obtained. Then, $V\left(\Delta I_{i}\right)=\Delta I_{i}{ }^{\alpha}, \Delta I_{i}=3.484$, and $I_{1}=I_{2}=I_{3}=3.484$ are obtained.

\subsubsection{Calculation of Information Value $U$}

Finally, we can calculate information value $U$ when the case of the value of a reference point is three. By using the value factor $I_{0}=3.484$ and the Formula (3), $\Delta I_{1}=1.516, \Delta I_{2}=0.516, \Delta I_{3}=-0.484$ are obtained. Then, using (1) and (2); $\Delta I_{1}=1.516, \Delta I_{2}=0.516, \Delta I_{3}=-0.484$; and $W_{1}=0.4167$, $W_{2}=0.3333, W_{3}=0.25$, the result of information value $U=0.49$.

\subsection{Outline of the Behavior of the Application}

Figure 14 shows the outline of the behavior of the application.

A beacon sends a beacon ID to a smartphone. The information value is calculated in the smartphone, and the list of information based on the information value is generated in descending order. Then, the list is sent to a wearable device such as a smartphone. The information with the highest priority is displayed on the wearable device, and the audio information is provided. A tourist can add "Good" or "Not Good" to the presented information. A tourist also can see other information on a list and can do it the same way. If the "Good" or "Not Good" is provided, a reference point of information is updated based on a tourist's action. A reference point is also calculated for each category classified by Maslow's hierarchy of needs in a location near a BLE beacon.

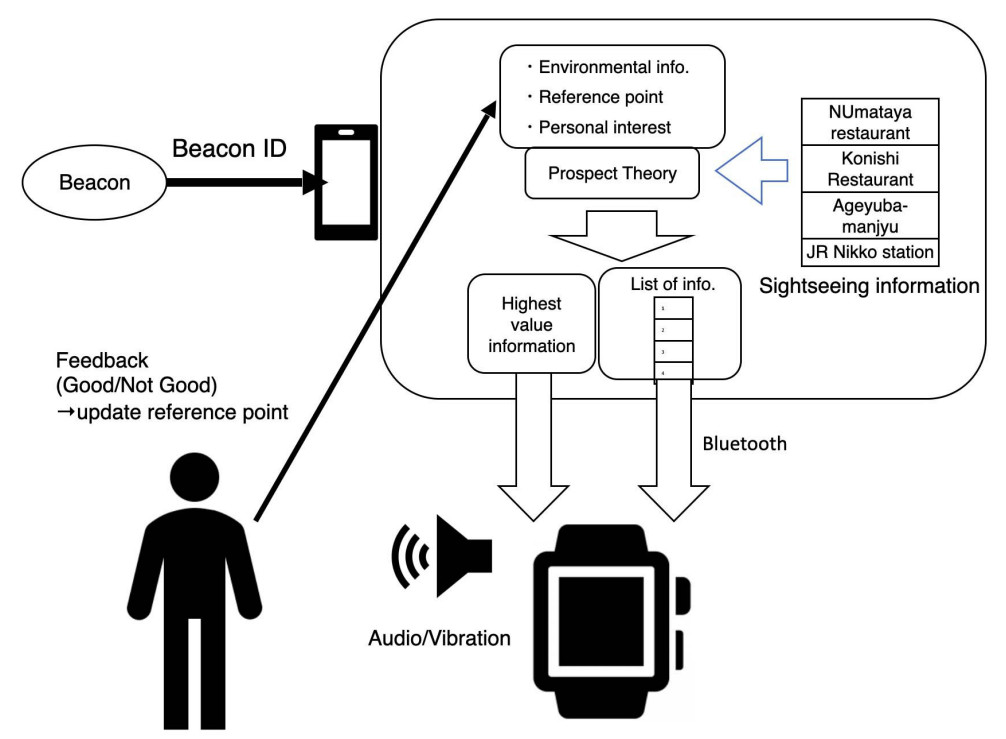

Figure 14. Outline of the behavior of the application.

\subsection{Simulation of Calculation of the Information Value}

In this subsection, we explain a simulation result of changing information value. We assume that the location of the BLE beacon is "Hatsuishi", which is a round rock where "Shodo-Shonin", the founder of Nikko, performed Buddhism training. The rock is located close to the main road, and a few people visit there regularly. We set four critical pieces of sightseeing information near "Hatsuishi", as described in Table 11. The original value and modified value, according to the value of reference points. In this case, the value of the reference points, i.e., 2, 3, and 4, are shown in Table 12. Table 13 shows the log of information value during the experiment. At this location, we did not set information in the category of "Love and belongingness needs". The maximum information value is different for each tester (indicated by * in the table). Each tester received different information based on their interest, desire, and behavior. 
Table 11. Parameters of simulation.

\begin{tabular}{ll}
\hline Level of Needs & Contents \\
\hline (1) Biological and physiological needs & Yoshida-ya "yokan" sweets shop, Natural food restaurant "Kai" \\
(3) Love and belongingness needs & Kimono rental shop "Utakata" \\
(6) Aesthetic needs & Hatsuishi \\
\hline
\end{tabular}

Table 12. Information value at reference points 2,3 , and 4 .

\begin{tabular}{clcccc}
\hline Level of Needs & Information & $\begin{array}{c}\text { Original } \\
\text { Information Value }\end{array}$ & $\begin{array}{c}\text { Reference } \\
\text { Point 2 }\end{array}$ & $\begin{array}{c}\text { Reference } \\
\text { Point 3 }\end{array}$ & $\begin{array}{c}\text { Reference } \\
\text { Point 4 }\end{array}$ \\
\hline 1 & $\begin{array}{l}\text { Yoshida-ya “yokan" } \\
\text { sweets shop }\end{array}$ & 2.75 & 0.881 & -0.94 & -3.492 \\
\hline 1 & $\begin{array}{l}\text { Natural food } \\
\text { restaurant “Kai" }\end{array}$ & 3.062 & 1.312 & -0.191 & -2.736 \\
\hline 3 & $\begin{array}{l}\text { Kimono rental shop } \\
\text { “Utakata” }\end{array}$ & 3.218 & -0.274 & -0.274 & -0.274 \\
\hline 6 & Hatsuishi & 2.432 & -1.689 & -1.689 & -1.689 \\
\hline
\end{tabular}

Table 13. Some personalized information values (some of them). ${ }^{*}$ means the highest value.

\begin{tabular}{|c|c|c|c|c|c|}
\hline Tester ID & & $\begin{array}{l}\text { Yoshida-Ya "Yokan" } \\
\text { Sweets Shop }\end{array}$ & $\begin{array}{c}\text { Natural Food } \\
\text { Restaurant "Kai" }\end{array}$ & $\begin{array}{l}\text { Kimono Rental } \\
\text { Shop “Utakata” }\end{array}$ & Hatsuishi \\
\hline \multirow[t]{2}{*}{$\mathrm{A}$} & Reference point & 2 & 2 & 4 & 4 \\
\hline & Value & 0.881 & $1.312 *$ & -2.171 & -3.378 \\
\hline \multirow[t]{2}{*}{ B } & Reference point & 3 & 3 & 3 & 3 \\
\hline & Value & -0.422 & 0.208 & 0.279 * & -0.857 \\
\hline \multirow[t]{2}{*}{$\mathrm{C}$} & Reference point & 5 & 5 & 3 & 3 \\
\hline & Value & -2.376 & -1.901 & -0.274 * & -1.689 \\
\hline \multirow[t]{2}{*}{$\mathrm{D}$} & Reference point & 3 & 3 & 3 & 3 \\
\hline & Value & -0.036 & $0.506^{*}$ & -0.522 & -0.857 \\
\hline \multirow[t]{2}{*}{$\mathrm{E}$} & Reference point & 5 & 5 & 3 & 3 \\
\hline & Value & -3.25 & -2.628 & -0.615 & $-0.274 *$ \\
\hline
\end{tabular}

\section{Experiment of Application Using Prospect Theory}

\subsection{Outline of the Experiment}

The experiment aimed to conform to the effectiveness to provide appropriate sightseeing information to meet the traveler's situation. We performed two experiments to evaluate the sightseeing application. The outline is described in Figure 15.

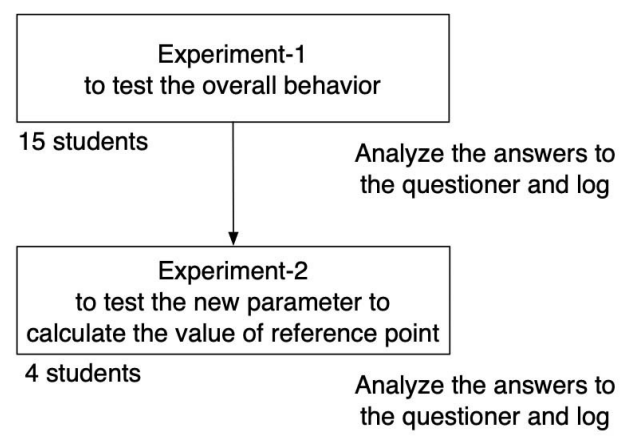

Figure 15. Outline of the experiment. 
The first experiment was carried out on 9 and 10 December 2019. Fifteen students from Utsunomiya University participated in this experiment. Nine examinees used smartwatches (Apple Watch), and six examinees did not use them. The second experiment was carried out on 18 March 2020. Four students from Utsunomiya University joined this experiment, and all of them wore smartwatches (Apple Watch). Because of COVID-19, the large-scale experiment was not allowed by the university and government, so we experimented to confirm the parameters' effect to calculate the information value using the Prospect Theory.

We evaluated the application by the following points.

- Awareness of BLE beacon

- Change of value of the reference point

- Distribution of information value

- Evaluation of the delivered information

- Change of image of Nikko

Figure 16 shows the route of experiments from Nikko Station to Toshogu Shrine. There were 13 BLE beacons on the route, and the distance between two beacons was about $100 \mathrm{~m}$.

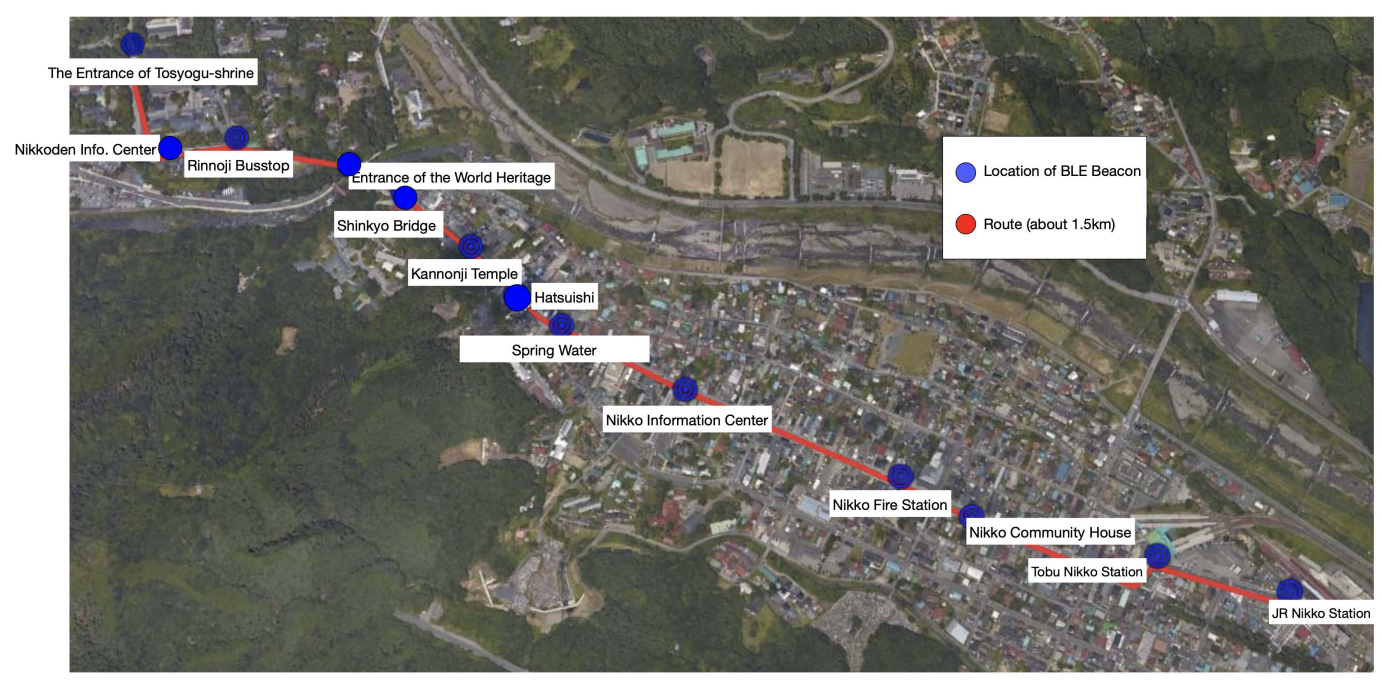

Figure 16. Experiment route.

\subsection{Awareness of BLE Beacon}

Figure 17 shows the number of noticed BLE beacons by the smartwatch users in the trials. In experiment 1 , the average number of noticed BLE beacons was $10.3(79.2 \%)$, and $11.9(91.5 \%)$ in experiment 2. We think the number of noticed BLE beacon was not bad. The BLE beacon was installed every $100 \mathrm{~m}$ so that if a traveler missed receiving a signal from a BLE beacon, he/she could recover to get sightseeing information.
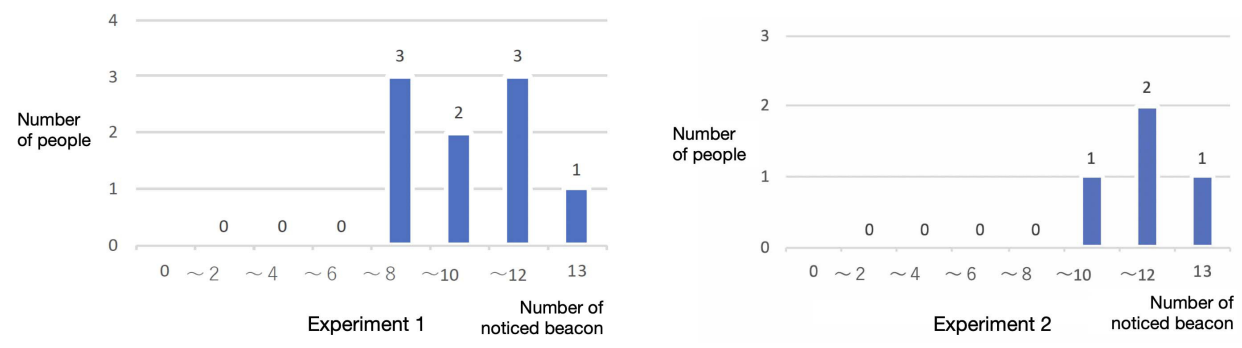

Figure 17. The number of noticed BLE beacons. 


\subsection{Change of Value of the Reference Point}

The reference point was changed according to the rule.

Figures 18 and 19 shows the history of changing the value of reference points by the responses of the testers in experiment 1 and 2, respectively. Each tester shows a different trend. The calculated information value differs according to based on the reaction of the presented information. This result displays that each tester received personalized and optimal sightseeing information according to their needs.

However, the shape of the graph is a little bit different. In experiment 1 , the graphs become flat because we used parameter different from Table 6 as described in Table 14. After modifying the parameter, the value of the reference point followed the tester's responses.

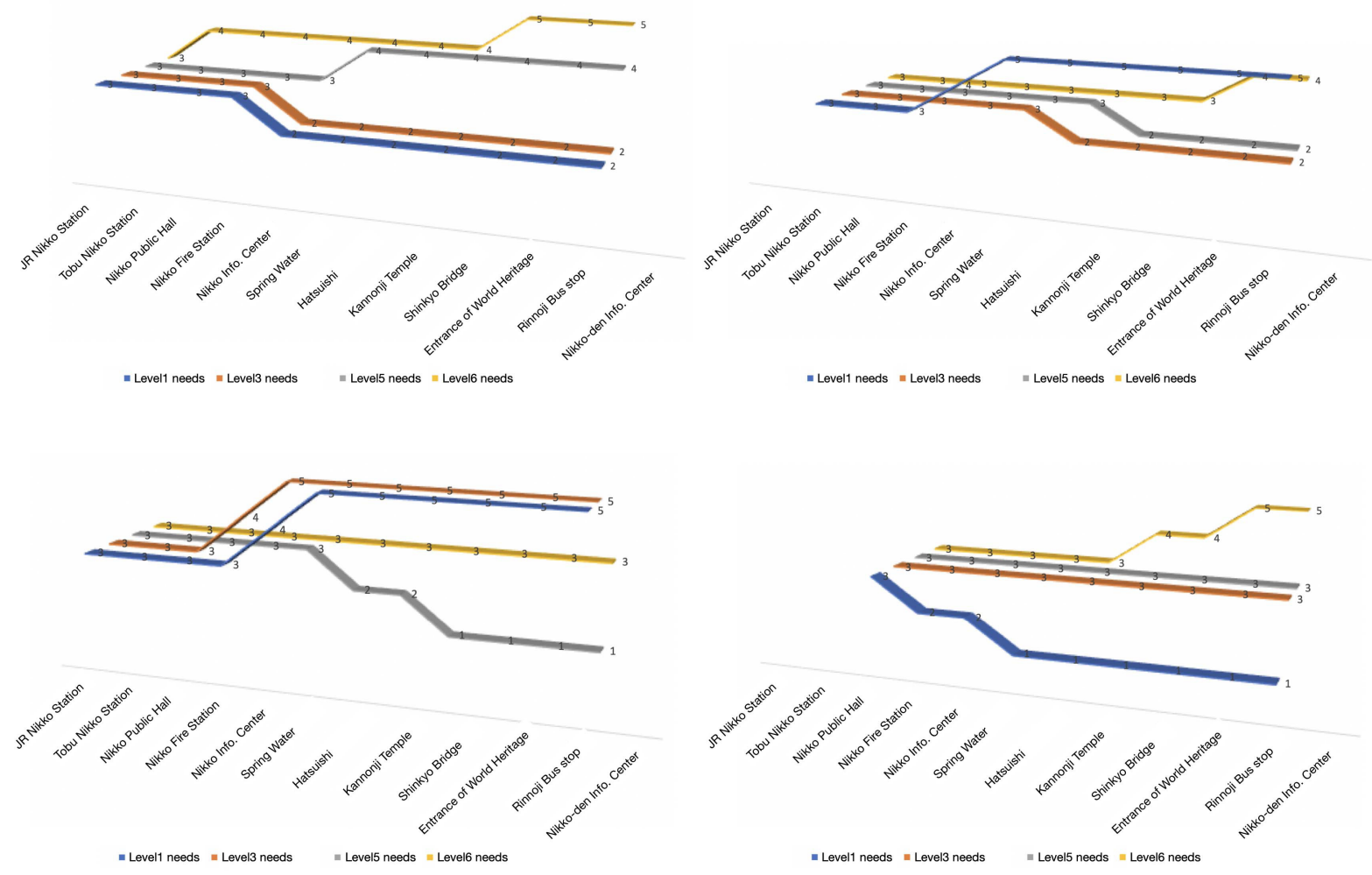

Figure 18. History of changing the value of the reference points: Experiment 1.

Table 14. Old parameters to change the value of reference point.

\begin{tabular}{cccc}
\hline \multirow{2}{*}{ Change of Reference Point } & & \multicolumn{2}{c}{ Information } \\
\cline { 3 - 4 } & & Responded & Not Responded \\
\hline \multirow{2}{*}{ Evaluation } & Good & 0 & 1 \\
& Not Good & -1 & 0 \\
\hline
\end{tabular}




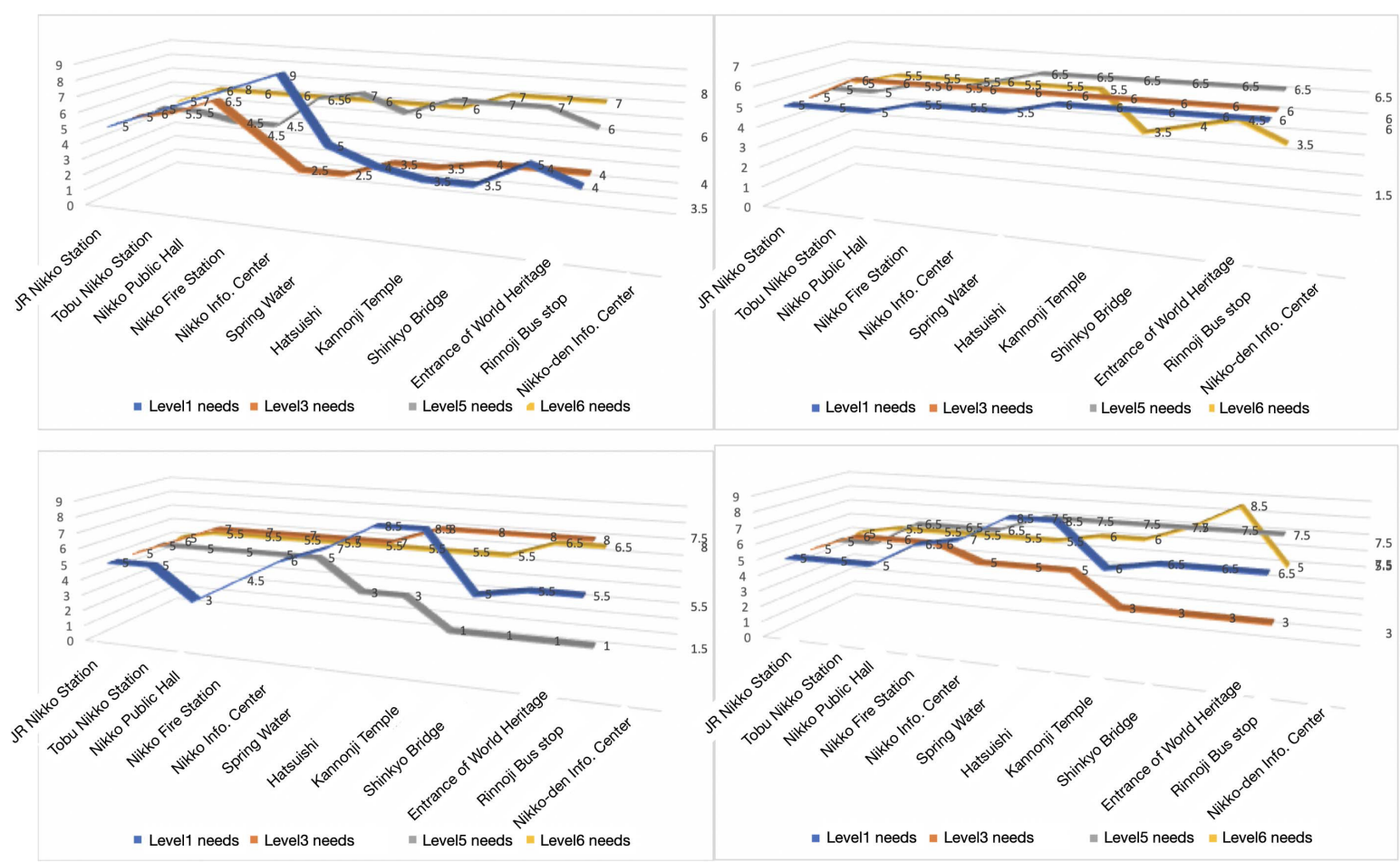

Figure 19. History of changing the value of the reference points: Experiment 2.

\subsection{Distribution of Information Value}

Figure 20 shows the average of each category's information value. If the size is large, the largest circle category has a higher value in this area.

In experiment 1, just after starting from Nikko station, love and belongingness needs were dominant, then biological and physiological needs were dominant. However, near the Kannonji Temple and Shinkyo Bridge, the value of information relating to cognitive needs and aesthetic needs became dominant.

In experiment 2, the result shows that the average information value is higher between the JR Nikko Station and Fire Station. On the other hand, the average information value decreased between the Fire Station and Toshogu Shrine. This experiment's weather condition was cold and windy, so the testers required information on the "biological and physiological needs" and not "aesthetic needs".

Therefore, we think this application can provide appropriate information by following the intention of a user.

\subsection{Evaluation of the Delivered Information}

Figure 21 shows the result of evaluation of the delivered information. In experiment 1, 90 sets of information were received from the testers. Out of those, 48 pressed "Like" (53\%), 19 pressed "Not Good" (21\%), and 23 with no action. Also, 58 information, they pressed "Like". In total, they pressed "Like" 106 times. If they pressed "Not Good", it worked to change the value of the reference point actively.

In experiment 2, 48 sets of information were received from the testers. Out of those, 32 pressed "Like" (67\%), 13 pressed "Not Good" (27\%), and three with no action. Moreover, in 55 sets of information they pressed "Like". In total, they pressed "Like" 87 times.

After changing the parameter to change the reference point's value, the information value was better, and the testers would like to respond to the delivered information. 

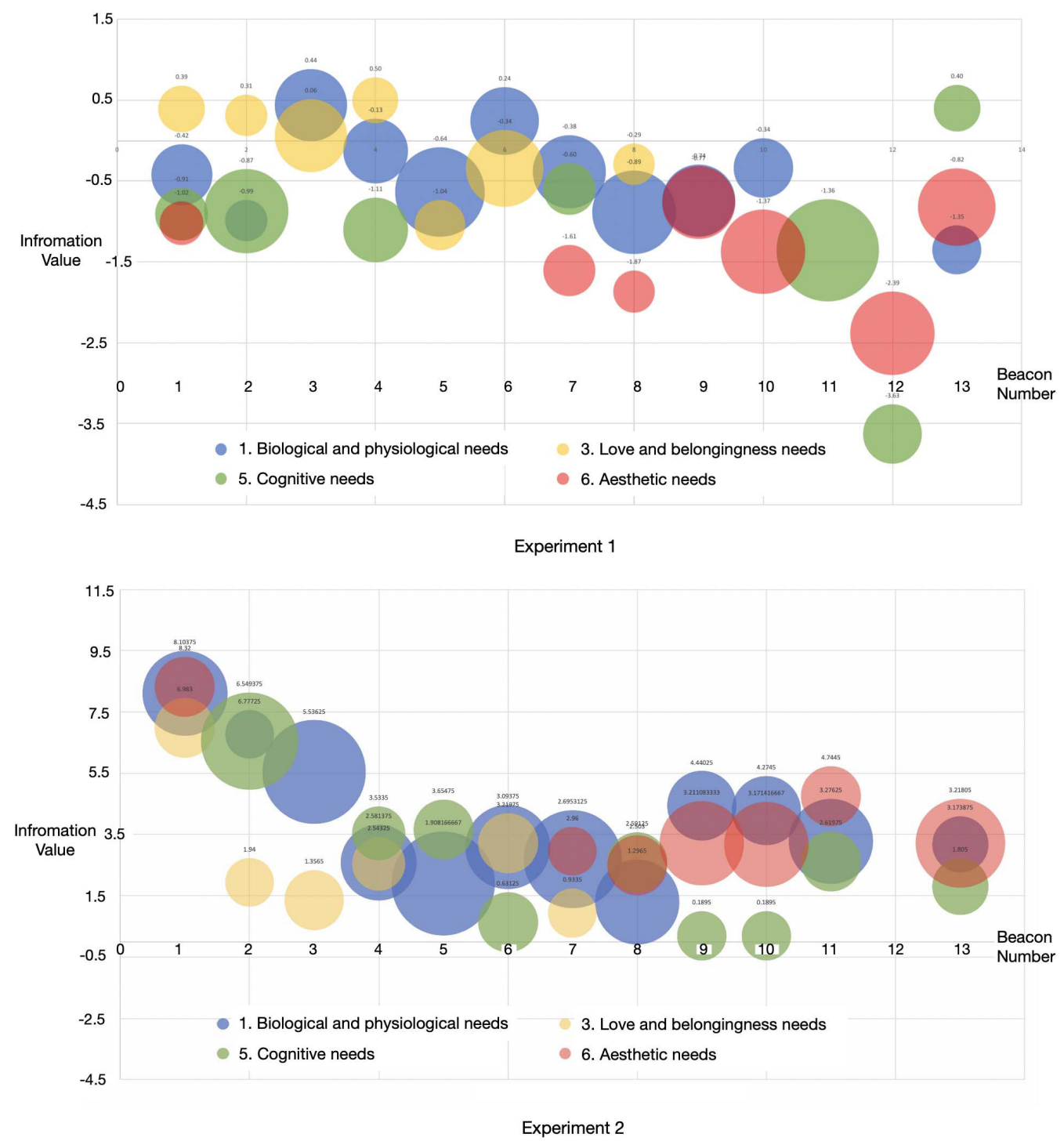

Figure 20. Bubble chart of the information value.

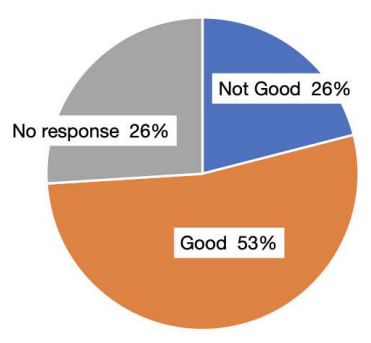

Experiment 1

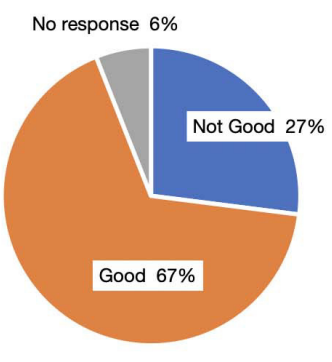

Experiment 2

Figure 21. The result of evaluation of the delivered information.

\subsection{Change of Image of Nikko}

We asked the testers to answer the questionnaire about the image of Nikko before and after the experiment. The questionnaire is shown in Figure 22. Each tester makes a check on the line between two words. Figure 23 shows the result of the questionnaire. A dotted square represents positive feelings, and a solid square represents negative feelings. 
In experiment 1, after using this application, they answered positively to the positive items and negatively to the negative items, except "silent" whether they used a smartwatch or not. We think the reason they felt not silent was that the application proposed information not only on the screen but also as audio because of being unable see the screen to avoid "walking with smartphone". In experiment 2 , the response was similar. The difference was "global". We intended to design this application to provide information to inbound travelers. After refining the parameters, the application could provide a variety of information that reflects Nikko's tradition.

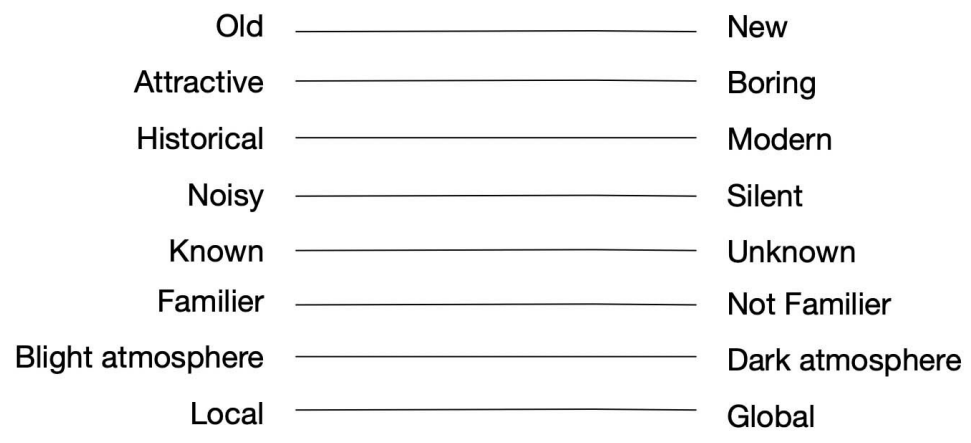

Figure 22. Questionnaire about the image of Nikko.
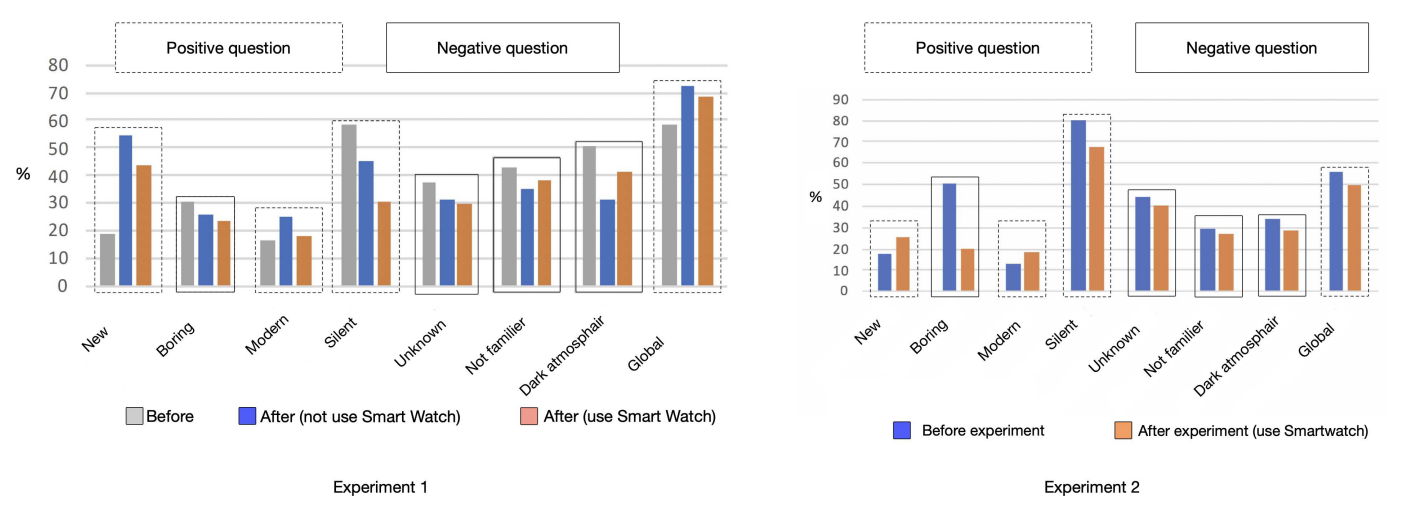

Figure 23. Change of image of Nikko.

\section{Conclusions}

In this paper, we described the result of our research on a sightseeing support application that applies psychological effects to realize the optimal provision of sightseeing information. First, we explain the history of this project and previous results about the effectiveness of introducing the Zeigarnik effect and Maslow's hierarchy of needs. However, the previous studies could not provide the appropriate sightseeing information to a traveler during a trip. We started a study to solve that problem by using the Prospect Theory and Maslow's hierarchy of needs. We designed and evaluated an application that provides sightseeing information according to the changes in desires during the trip. By the experiments, we proved that the information value could be changed according to a traveler's behavior and provide appropriate information to a traveler. Moreover, we confirmed that the user of this application could have a good image of the destination. We showed that by combining the psychological effects and location information provided by BLE beacons, we could deliver optimal information according to different needs, encourage people to look around, and as a result, increase satisfaction levels. By further improving the accuracy of the information provided, we would like to develop a technology that allows tourists to enjoy scenery and cultural properties by providing an experience of walking with a support guide without looking at a smartphone. Moreover, we found that wearable devices such as smartwatches are useful to provide sightseeing information to a traveler during a trip. In tourist spots, we sometimes follow the screen of smartphones or smartwatches 
without acknowledging the beautiful scenery, historic buildings, townscapes, etc. The screens of mobile devices distract tourists during a sightseeing trip.

We also displayed the effectiveness of using a smartwatch for information delivery. We think that the usefulness of the CogInfoCom model's extension with "intra-cognitive informatics" is explained in Section 3.

As future work, we would like to perform the next experiment using the latest version of our application as currently we cannot complete the experiment because of COVID-19.

Author Contributions: Conceptualization, A.S., Y.H. (Yasunari Harada) and A.I.; methodology, A.S., K.U., Y.H. (Yuko Hiramatsu) and A.I; software, A.S., R.H. and F.X.; validation, A.S., R.H. and F.X.; formal analysis, A.S., Y.H. (Yuko Hiramatsu), R.H. and F.X.; investigation, A.S., Y.H. (Yuko Hiramatsu), R.H., F.X., H.H. (Hiroyuki Hatano) and A.I.; resources, H.H. (Hiroyuki Hatano); data curation, A.S., Y.H. (Yuko Hiramatsu), R.H. and F.X.; writing-original draft preparation, A.S.; writing-review and editing, A.I.; visualization, Y.H. (Yuko Hiramatsu), R.H. and F.X.; supervision, H.H. (Hiroyuki Hatano), H.H. (Hiroshi Hasegawa) and A.I.; project administration, A.I.; funding acquisition, Y.H. (Yuko Hiramatsu) and A.I. All authors have read and agreed to the published version of the manuscript.

Funding: This research is supported by JSPS KAKENHI Grant Number JP17H02249 and JP18K111849. Moreover, the basis of this research was performed as a project of SCOPE (142303001).

Acknowledgments: The authors would like to express special thanks to Wada and Suzuki of Nikko National Park Office of the Ministry of the Environment, Wada and Sato of Tochigi Prefectural Government Office, and all members of the committee for increasing the satisfaction of tourists in Nikko. They provided us information about Oku-Nikko and valuable advice. The authors also would like to express special thanks to Funakoshi, who was a manager of the Nikko Tourism Association. We also thank Takamura and Yoshida of Hatsuishi-kai that is an association of shops in Nikko, Nakagawa of Kounritsuin Temple, and Nagai who is a Professor Emeritus of Utsunomiya University.

Conflicts of Interest: The authors declare no conflict of interest.

\section{References}

1. Japan Tourism Agency. The Tourism Nation Promotion Basic Plan. Available online: https://www.mlit.go. jp/kankocho/en/kankorikkoku/kihonkeikaku.html (accessed on 5 October 2020).

2. ICT-Based Innovation and Economic Growth, White Paper on Information and Communications 2016. Available online: https://www.soumu.go.jp/johotsusintokei/whitepaper/eng/WP2016/chapter-1.pdf (accessed on 5 October 2020).

3. Tae-Hee, L.; Crompton, J. Measuring Novelty Seeking in Tourism. Ann. Tour. Res. 1992, 19, 732-751

4. Salazar, N.B. Enough stories! Asian tourism redefining the roles of Asian tour guides. Civilisations 2008, LVII, 207-222 [CrossRef]

5. Tomikawa, K. Validity of guided tours on tourist resources. Kyoto Sosei Univ. Rev. 2007, 7, 69-77

6. Fine, E.C.; Speer, J.H. Tour Guide Performance as Sight Sacralization. Ann. Tour. Res. 1985, 12, 73-95 [CrossRef]

7. Blyablina, A. The Contribution of Guides in Developing Tourist Experiences during Historical Theatrical Tours: The Case of Stockholm Ghost Walk. Master's Thesis, Mid Sweden University, Faculty of Human Sciences, Department of Tourism Studies and Geography, Ostersund, Sweden, 2015.

8. Vroom, V.H. Work and Motivation; Wiley: New York, NY, USA, 1964

9. Lawler, E.E.; Suttle, J.L. A causal correlational test of the need hierarchy concept. Organ. Behav. Hum. Perform. 1972, 7, 265-287 [CrossRef]

10. Maslow, A.H. Motivation and Personality, 3rd ed.; Pearson Education: Delhi, India, 1987.

11. Ajzen, I.; Fishbein, M. The prediction of behavioral intentions in a choice situation. J. Exp. Soc. Psychol. 1969, 5, 400-416. [CrossRef]

12. Bearden, W.O.; Woodside, A.G. Testing variations of Fishbein's behavioral intention model within a consumer behavior context. J. Appl. Psychol. 1977, 62, 352-357. [CrossRef]

13. Kagawa, M. An Empirical Study of Motivation to Travel by Expectancy Theory Model(I). Bull. Inst. Ind. Res. Osaka Ind. Univ. 1979, 2, 49-76. 
14. Sasaki, T. An analytical report drawn from the results of two exploratory studies in the field of the psychology of tourist behavior: Some empirical findings of surveys of university students. Bull. Fac. Sociol. Kansai Univ. 2005, 37, 79-108.

15. Sasaki, T. Psychology of Sightseeing; Kitaoji-Syobo: Kyoto, Japan, 2007; pp. 62-63, ISBN 978-4-7628-2542-2.

16. Masuda, M.; Izumi, T.; Nakatani, Y. A System that Promotes Repeat Tourists by Making Sightseeing Unfinished. Trans. Hum. Interface Soc. 2012, 14, 259-270.

17. Zeigarnik, B.V. On finished and unfinished tasks. In A Sourcebook of Gestalt Psychology; Ellis, W.D., Ed.; Humanities Press: New York, NY, USA, 1967.

18. Yanga, J.; Jiang, G. Development of an enhanced route choice model based on cumulative prospect theory. Transp. Res. Part C Emerg. Technol. 2014, 47, 168-178. [CrossRef]

19. Avineri, E.; Bovy, P.H.L. Identification of Parameters for a Prospect Theory Model for Travel Choice Analysis. Transp. Res. Rec. J. Transp. Res. Board 2008, 2082, 141-147. [CrossRef]

20. Gretzel, U.; Sigala, M.; Xiang, Z.; Koo, C. Smart tourism: Foundations and developments. Electron. Mark. 2015, 25, 179-188. [CrossRef]

21. Gretzel, U.; Werthner, H.; Koo, C.; Lamsfus, C. Conceptual foundations for understanding smart tourism ecosystems. Comput. Hum. Behav. 2015, 50, 558-563. [CrossRef]

22. Josep, A.; Ivars-Baidal, J.A.; Celdran-Bernabeu, M.A.; Jose-Norberto, M.; Angel, F.P. Smart destinations and the evolution of ICTs: A new scenario for destination management? Curr. Issues Tour. 2019, 22, 1581-1600. [CrossRef]

23. Neuhofer, B.; Buhalis, D.; Ladkin, A. Smart technologies for personalized experiences: A case study in the hospitality domain. Electron. Mark. 2015, 25, 243-254. [CrossRef]

24. Da Costa, Liberato, P.M.; Alen-Gonzalez, E.; de Azevedo Liberato, D.F.V. Digital Technology in a Smart Tourist Destination: The Case of Porto. J. Urban Technol. 2018, 25, 75-97. [CrossRef]

25. Buhalis, D. Technology in tourism-from information communication technologies to eTourism and smart tourism towards ambient intelligence tourism: A perspective article. Tour. Rev. 2020, 75, 267-272. [CrossRef]

26. Yoo, C.W.; Goo, J.; Huang, C.D.; Nam, K.; Woo, M. Improving travel decision support satisfaction with smart tourism technologies: A framework of tourist elaboration likelihood and self-efficacy. Technol. Forecast. Soc. Chang. 2017, 123, 330-341. [CrossRef]

27. Tourism Informatics. IPSJ Magazine 2012, 53, 1134-1209.

28. Kurata, Y. Current Situation of "Local Smartphone Applications" for Tourists. J. Jpn. Soc. Artif. Intell. 2016, 31, 839-843.

29. Anacleto,R.; Figueiredo, L.; Almeida, A.; Novais, P. Mobile application to provide personalized sightseeing tours. J. Netw. Comput. Appl. 2014, 41, 56-64. [CrossRef]

30. Smirnov, A.V.; Kashevnik, A.M.; Ponomarev, A. Context-based infomobility system for cultural heritage recommendation: Tourist Assistant-TAIS. Pers. Ubiquitous Comput. 2017, 21, 297-311. [CrossRef]

31. Trygg, N.B.; Luimula, M. Cultural heritage in a pocket: Case study "Turku castle in your hand". In Proceedings of the 2016 7th IEEE International Conference on Cognitive Infocommunications (CogInfoCom), Wroclaw, Poland, 16-18 October 2016; pp. 55-58. [CrossRef]

32. Bluetooth 4.0 Specification. Available online: https://www.bluetooth.com/ja-jp/specifications/archivedspecifications / (accessed on 30 November 2020).

33. Ito, A.; Hiramatsu, Y.; Hatano, H.; Sato, M.; Fujii, M.; Watanabe, Y.; Sato, F.; Sasaki, A. Navigation system for sightseeing using BLE beacons in a historic area. In Proceedings of the 2016 IEEE 14th International Symposium on Applied Machine Intelligence and Informatics (SAMI), Herlany, Slovakia, 21-23 January 2016; pp. 171-176. [CrossRef]

34. Spachos, P.; Plataniotis, K.N. BLE Beacons for Indoor Positioning at an Interactive IoT-Based Smart Museum. IEEE Syst. J. 2020, 14, 3483-3493. [CrossRef]

35. Huang, K.; He, K.; Du, X. A Hybrid Method to Improve the BLE-Based Indoor Positioning in a Dense Bluetooth Environment. Sensors 2019, 19, 424. [CrossRef]

36. Macik, M.; Maly, I.; Lorencova, E.; Flek, T.; Mikovec, Z. Smartphoneless context-aware indoor navigation. In Proceedings of the 2016 7th IEEE International Conference on Cognitive Infocommunications (CogInfoCom), Wroclaw, Poland, 16-18 October 2016; pp. 163-168. [CrossRef] 
37. Rios, S.; Cabrera-Umpierrez, M.F.; Arredondo, M.T.; Paramo, M.; Baranski, B.; Meis, J.; Gerhard, M.; Prados, B.; Perez, L.; Villafranca, M.M. Using Augmented Reality and Social Media in Mobile Applications to Engage People on Cultural Sites. In Universal Access in Human-Computer Interaction. Universal Access to Information and Knowledge; Springer International: Cham, Switzerland, 2014; Volume 8514, ISBN 978-3-319-07439-9.

38. Baranyi, P.; Csapo, A. Definition and Synergies of Cognitive Infocommunications. Acta Polytech. Hung. 2012, 9,67-83.

39. Baranyi, P.; Csapo, A.; Sallai, G. Cognitive Infocommunications (CogInfoCom); Springer International: Cham, Switzerland, 2015; ISBN 978-3-319-19607-7.

40. Ito, A.; Hayashi, R.; Hatano, H.; Shoji, K.; Sato, M.; Hiramatsu, Y.; Sato, F.; Ueda, K.; Harada, Y.; Morishita, M.; et al. A Cognitive Model of Sightseeing for Mobile Support System. In Proceedings of the 2017 8th IEEE International Conference on Cognitive Infocommunications (CogInfoCom), Debrecen, Hungary, 11-14 September 2017; pp. 57-62. [CrossRef]

41. Information of Nikko. 2020. Available online: http://www.city.nikko.lg.jp.e.tj.hp.transer.com(accessed on 30 November 2020).

42. Introduction of Toshogu. 2020. Available online: http://www.toshogu.jp/english/index.html (accessed on 30 November 2020).

43. The Most Popular Spot for Visitors to Japan 2015. Trip Advisor. 2015. Available online: http://tg.tripadvisor. jp/news/ranking/inboundattraction_2015/(accessed on 30 November 2020).

44. Ito, A.; Hatano, H.; Fujii, M.; Sato, M.; Watanabe, Y.; Hiramatsu, Y.; Sato, F.; Sasaki, A. A trial of navigation system using BLE beacon for sightseeing in traditional area of Nikko. In Proceedings of the 2015 IEEE International Conference on Vehicular Electronics and Safety (ICVES), Yokohama, Japan, 5-7 November 2015; pp. 170-175. [CrossRef]

45. Hiramatsu, Y.; Sato, F.; Ito, A.; Hatano, H.; Sato, M.; Watanabe, Y.; Sasaki, A. A Study of Designing Service Model for Sightseeing Using BLE Beacons-To Provide Tourism Information of Traditional Cultural Sites. Int. J. Adv. Intell. Syst. 2016, 9, 442-451.

46. Hiramatsu, Y.; Sato, F.; Ito, A.; Hatano, H.; Sato, M.; Watanabe, Y.; Sasaki, A. Designing Mobile Application to Motivate Young People to Visit Cultural Heritage Sites. Int. J. Soc. Behav. Educ. Econ. Bus. Ind. Eng. 2017, 11, 121-128.

47. Hiramatsu, Y.; Ito, A. A Study of Sightseeing Support System Using ICT Based on Attitude Surveys of Visitors to Nikko. Annu. Inst. Econ. Res. Chuo Univ. 2015, 46, 497-529.

48. McLeod, S.A. Maslow's Hierarchy of Needs. 2017. Available online: www.simplypsychology.org/maslow. html (accessed on 5 October 2020).

49. Ito, A.; Hayashi, R.; Hiramatsu, Y.; Sasaki, A. A study of designing process for tourism support mobile application applying psychological effects. IJRET Int. J. Res. Eng. Technol. 2018, 7, 58-70. [CrossRef]

50. Sasaki, A.; Ito, A.; Hayashi, R.; Hiramatsu, Y.; Ueda, K.; Harada, Y.; Morishita, M.; Hatano, H.; Sato, F. A Study of Psychological Approach to Design Sightseeing Support Mobile Application. In Proceedings of the 2018 IEEE 22nd International Conference on Intelligent Engineering Systems (INES), Las Palmas de Gran Canaria, Spain, 21-23 June 2018; pp. 87-92. [CrossRef]

51. Surprenant, A.M.; Neath, I. Principles of Memory; Psychology Press: London, UK, 2013.

52. Kahneman, D. Thinking, Fast and Slow; Farrar, Straus and Giroux: New York, NY, USA, 2011.

53. Tversky, A.; Kahneman, D. Advances in Prospect Theory:Cumulative Representation of Uncertainty. J. Risk Uncertain. 1992, 5, 297-323. [CrossRef]

54. Kahneman, D.; Tversky, A. Prospect Theory: An Analysis of Decision under Risk. Econometrica 1979, 47, 263-291. [CrossRef]

55. Yunna W.; Chuanbo X.; Ting Z. Evaluation of renewable power sources using a fuzzy MCDM based on cumulative prospect theory: A case in China. Energy 2018, 147, 1227-1239. [CrossRef]

Publisher's Note: MDPI stays neutral with regard to jurisdictional claims in published maps and institutional affiliations. 